\title{
Simulation analysis of the significance and interaction of influencing factors on mixing uniformity of double drum recycling mixing plant
}

Dengcheng Ma ( $\square$ mdc8235@163.com )

Chang'an University https://orcid.org/0000-0003-4063-0472

Chao Chen

AECC COMMERCIAL AIRCRAFT ENGINE CO.,LTD

Chengqi Liu

CHINA RAILWAY ENGINEERING EQIPMENT GROUP CO.,LTD

\section{Original Article}

Keywords: Double drum recycling mixing plant,EDEM, mixing uniformity, Response Surface Methodology, structural design

Posted Date: August 17th, 2021

DOl: https://doi.org/10.21203/rs.3.rs-806100/v1

License: (c) (i) This work is licensed under a Creative Commons Attribution 4.0 International License. Read Full License 


\section{Simulation analysis of the significance and}

2 interaction of influencing factors on mixing

3 uniformity of double drum recycling mixing

4 plant

Dengcheng $\mathrm{Ma}^{1} *$, Chao Chen ${ }^{2}$, Chengqi Liu ${ }^{3}$

${ }^{1}$ National engineering laboratory for road maintenance equipment, chang'an university, xi'an 710064, China;

${ }^{2}$ AECC COMMERCIAL AIRCRAFT ENGINE CO.,LTD, Shang'hai, 201100, China;

${ }^{3}$ CHINA RAILWAY ENGINEERING EQIPMENT GROUP CO.,LTD, Tian'jin, 450016, China.

Corresponding author: Dengcheng Ma（E-mail address: mdc8235@163.com） National engineering laboratory for road

maintenance equipment, Chang'an University, Nan Er Huan Zhong Duan, Xi’an 710064,Shaanxi, China..

11 ABSTRACT: The mixing uniformity of the double drum recycling mixing plant has an important

12 effect on the quality of recycled asphalt mixture. The mixing uniformity of the double drum

13 recycling mixing plant not only depends on the axial installation angle of the blade, the radial

14 installation angle of the blade, the phase angle of the stirring arm, the inclination angle of the drum,

15 and the rotation speed of the drum, but also on the interaction between these factors. In order to

16 further clarify the relationship between the mixing uniformity and the above factors, the

17 significance and interaction of influencing factors of mixing uniformity were studied based on

18 EDEM and response surface methodology (RSM). The result shows that the factors affecting the

19 mixing uniformity of the aggregates are significantly different when the aggregate size is different.

20 Therefore, when studying the mixing uniformity of a mixing plant, it is not comprehensive to

21 conduct research on a certain factor in a single-sided manner. Instead, the main factors and the

22 interaction between the factors should be considered comprehensively. 
23 Keywords: Double drum recycling mixing plant, EDEM, mixing uniformity, Response Surface

24 Methodology, structural design.

\section{Introduction}

26 The mixing uniformity of double drum recycling mixing plant largely determines the quality of the recycled asphalt mixture, and its structural parameters and working parameters have an important influence on the mixing uniformity of the asphalt mixture.Therefore, many scholars have conducted a lot of research. Ma et al [1] analyzed the influence of the single factor of structure parameter and working parameter on the uniformity of mixing. Liu et al [2] analyzed the stress of the recycled asphalt mixture in the double-drum recycling mixing plant, and qualitatively analyzed the accumulation of the mixture on the mixing blades, and determined the installation range of the blade inclination. Zhao et al [3] optimized the structure of the drying drum of the asphalt mixing equipment, and analyzed the parameter matching of the asphalt mixing machine blades based on the discrete element method (EDEM). SIMONS $\mathrm{T}$ A $\mathrm{H}$ et al [4] studied on the characterization of granular mixing in a helical ribbon blade blender. SAKAI M et al [5] evaluated the uniformity of solid mixing in an industrial blender based on the discrete element simulation. John Milstead et al [6] proposed an improvement to the shape of the mixing blade on the outer wall of the inner cylinder, which can extend the residence time of the mixture on the blade, increase the amount and height of the blade, and enhance the spraying and uniformity of the mixture. Larry W. Hudman et al [7] proposed a mixing chain device that can reduce the adhesion of the asphalt mixture on the outer surface of the inner cylinder to prevent the adhered aging materials from cracking and falling into the mixing chamber to contaminate the mixture. Based on the analysis of the structure and working principle of the double drum, I. Choustere [8] pointed out the advantages of the equipment in terms of exhaust emission. Ivica Androjic et al [9] analyzed the energy consumption in the production of hot-mix asphalt (batch mixing equipment). D. Peinado et al [10]analyzed the energy and exergy in an asphalt plant's rotary dryer.

Jon Elvar Wallevik et al [11] analyzed the shear rate inside a concrete truck mixer. Justas BRAŽIŪNAS [12] proposed parameters of technological processes for mixing of bitumen with mineral aggregates that occur in a bitumen batching system (BBS) are stochastic and impact on the composition of bitumen binder as well as physical and mechanical properties of the produced HMA mixture, namely, air void content, stability, flow and Marshall 
49 quotient. Henrikas Sivilevičius [13]simulated the composition of recycled hot-mix asphalt mixture produced in 50 asphalt mixing plant

51 Other aspects include: M. Mohajeri, Molenaar et al[14] performed elastic modulus, indirect tensile strength, and 52 fatigue strength tests on compacted cylindrical samples considering different RAP content and humidity. It shows 53 that when RAP has low humidity, the recycled mixture produced by double drum mixing equipment has better 54 mechanical properties than the recycled mixture produced by batch mixing equipment. Yu [15] analyzed the main 55 reasons for the deviation of the asphalt content caused by the ASTEC double-drum continuous recycling mixing 56 equipment, and proposed an improvement plan. Cao [16] pointed out that in actual production of double-drum 57 continuous recycling mixing plant, the moisture content of aggregate, the temperature of asphalt, and the addition of 58 recycled materials will all have a certain degree of influence on continuous metering and grading. Gao Xin [17] designed a set of two-stage dust removal system based on the structural characteristics of the double-drum 60 continuous regeneration mixing equipment, and used Fluent software to simulate and optimize the structure of the 61 flow field in the cyclone dust collector. Zhong [18] studied the continuous drum-type asphalt mixing plant metering system, process flow and metering method.

63 Chi [19] used continuous tracking to detect the production quality of the mixture and found that the double-drum 64 continuous regenerative mixing equipment has better mixing effect than the forced batch mixing equipment. Other 65 studies on the structural parameters of mixing equipment using the discrete element method are also mentioned $66[20][21][22][23][24]$.

67 Above research focuses on the optimization and improvement of the performance of the double-drum mixing 68 plant, and the mixing uniformity of the double-drum recycling mixing plant is its most important performance index.

69 The limited literature on the effect of structural parameters and working parameters on the uniformity of mixing is 70 only in the influence of a single parameter. In the actual mixing process, the uniformity of mixing is affected by the 71 interaction of the drum speed, drum inclination angle, blade axial installation angle, blade radial installation angle, 72 and phase angle of the mixing arm.

73 In the actual mixing process, the mixing uniformity of the mixing drum is affected by the interaction of its 74 structural parameters and working parameters.

75 For this reason, this paper establishes a simulation model based on the discrete element method (DEM) that meets 76 the actual working conditions. Based on the analysis of the influence of each single factor on the uniformity of 
aggregate mixing, a mathematical model between the discrete coefficient of aggregate and each factor is established

78 by using the response surface methodology (RSM), and the significant relationship between each factor and its interaction on the uniformity of aggregate were analyzed. Furthermore, the influences of the rotating speed of the

80 drum, the inclination angle of the drum, the axial installation angle of the blade, the radial installation angle of the

81 blade, the phase angle of the mixing arm and other factors on the mixing uniformity are studied, which provides a reference for further understanding of the mixing mechanism and reveals the movement law of particles on the mixing blade.

\section{Analysis of main influencing parameters}

85 The double drum is the core component of the double drum recycling mixing plant. The outer cylinder is fixed to the frame and installed at a certain angle with the ground. The inner cylinder is coaxial with the outer cylinder to form a mixing zone with the outer cylinder.

A discharge port is opened at the end of the inner cylinder near the burner, and a stirring blade is installed on the outside. The cold aggregate enters the inner cylinder from the feed port after proportioning, and moves toward the burner under the action of gravity. With the rotation of the inner cylinder, the super-heated aggregate continuously falls

91 into the mixing chamber from the discharge port at the end of the inner cylinder. Recycled materials, new asphalt, 92 recycled materials and powder are added to the mixing chamber from different cross-sections of the outer cylinder. The 93 aggregate is heated and stirred in the outer cylinder to form a recycled mixture, which realizes the recycling of old recycled materials.

\section{1 Blade installation angle}

96 The installation angle of the blade affects the mixing uniformity and efficiency through affecting the axial, radial, and circumferential movement of the mixture[1Error! Reference source not found.. Its radial angle and axial angle have an important influence on the performance of double drum recycling mixing plant, as shown in Fig.1. Where $\alpha$ is blade radial angle and $\beta$ is axial angle. Therefore, it is necessary to analyze the range of blade installation angle. 


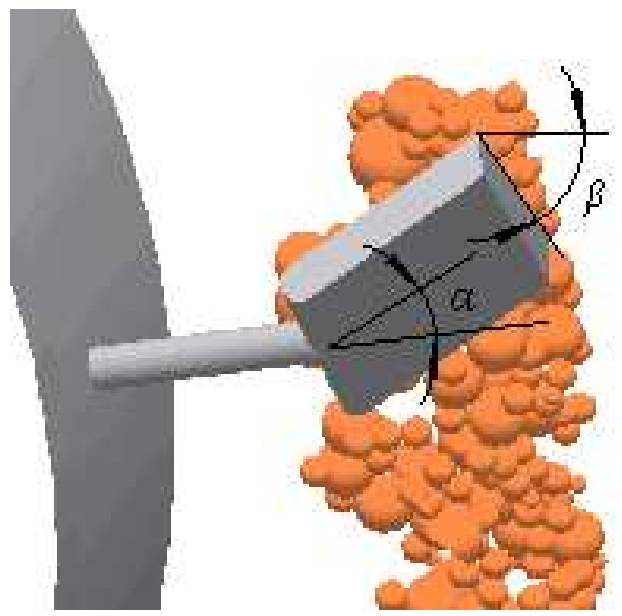

(a) Blade installation angle

(b) Mixture movement

FIGURE 1. blade mixing mixture 3D view.

105 When blade radial angle $\alpha=0^{\circ}$ and axial angle is $\beta$, The force analysis of the mixing unit on the blade is shown 106 in Fig.2(a). When $\beta=\gamma$, and blade radial angle is $\alpha$, the force analysis of the mixing unit on the blade is shown in 107 Fig.2(b). Where $F$ is the force on the asphalt mixture, $f$ is friction between blade and aggregate, $F_{1}$ is axial force, it 108 mainly causes the axial movement of the mixture. $F_{2}$ is tangential force, it mainly causes the circumferential movement 109 of the mixture. $F_{3}$ is radial force, it mainly causes radial movement of the mixture. $F_{4}$ is tangential force, it mainly 110 causes circumferential motion of the mixture. As shown in Fig.3, in order to realize the axial movement of the 111 mixture, it will meet the requirements: $F_{1}-f \geq 0, \beta \geq \arctan \mu$. Where $\mu$ is friction coefficient. For the same reason, 
112 the condition for the mixture to achieve radial movement shall be: $\alpha \geq \arctan \mu$.

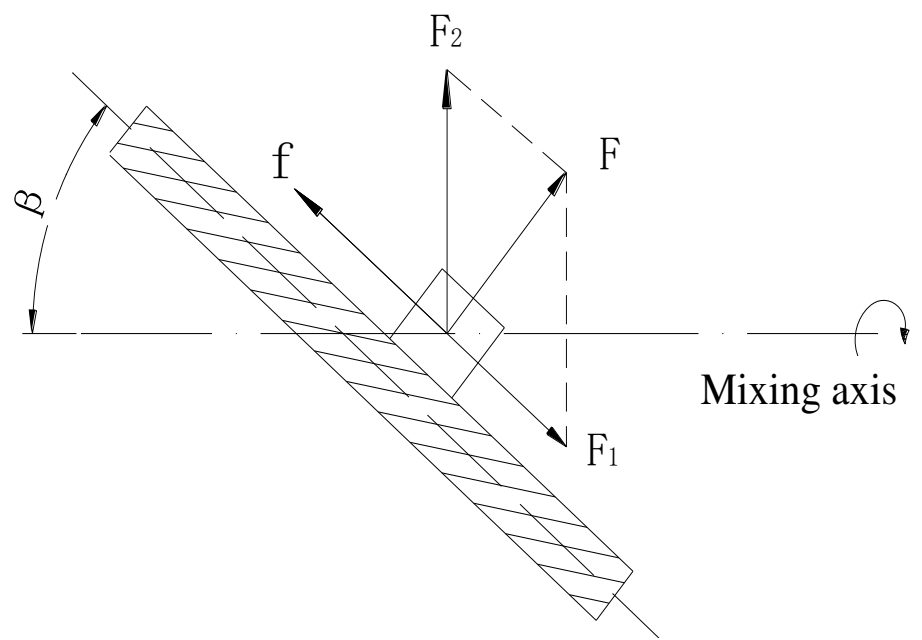

113

(a) Axial direction

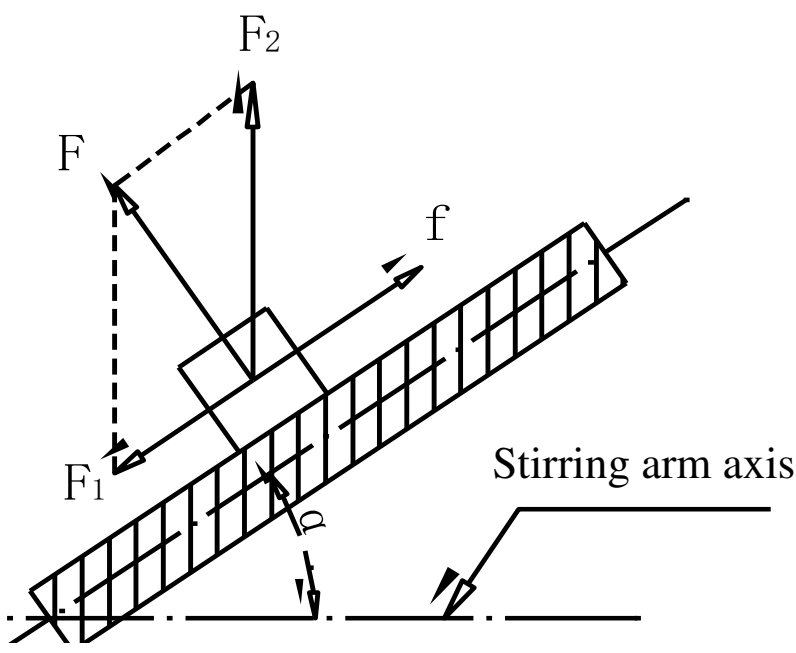

(b) Radial direction

FIGURE 2. The force analysis of the mixing unit.

118 Material pile formed on the face of blade during mixing as shown in Fig.3, where $\mathrm{AB}$ and $\mathrm{BC}$ are the side edges of 119 the pile, the mixture moves along the side edges. $\beta$ is the axial installation angle of the blade, $\gamma$ is the angle of the 120 drum; $W$ is the width of the blade;b is blade height; and $\theta$ is the angle between the side edges of the pile and the 121 horizontal plane, that is, the mixture accumulation angle. 


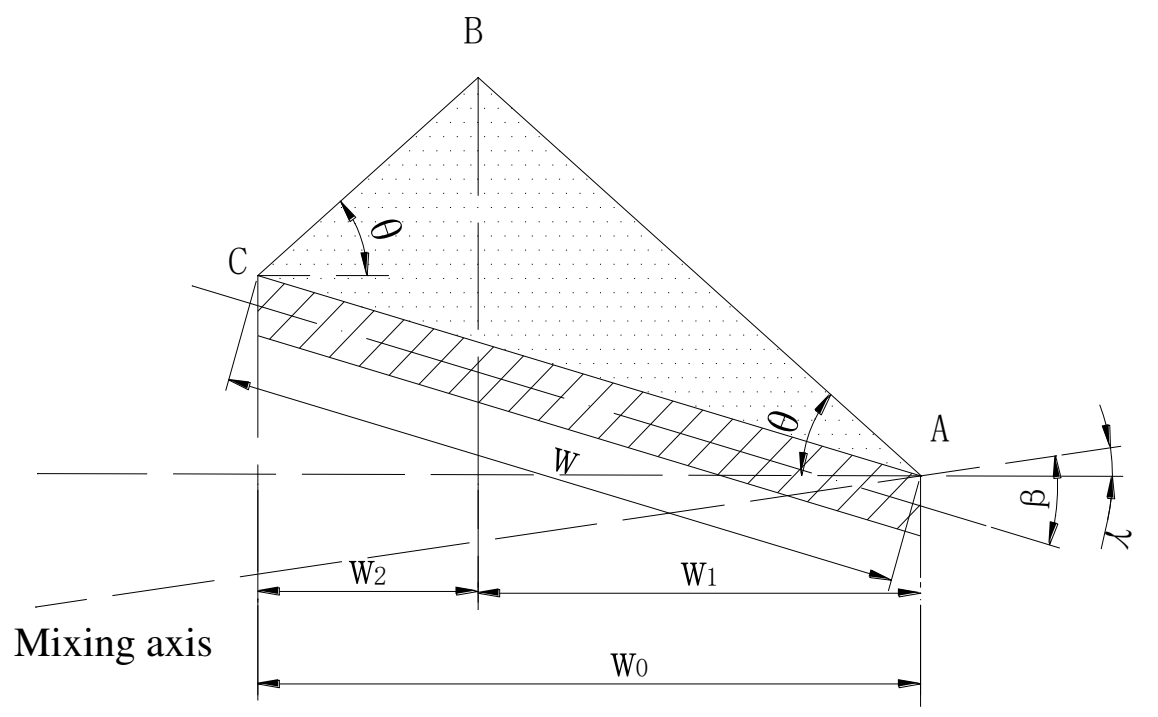

(a) Axial direction

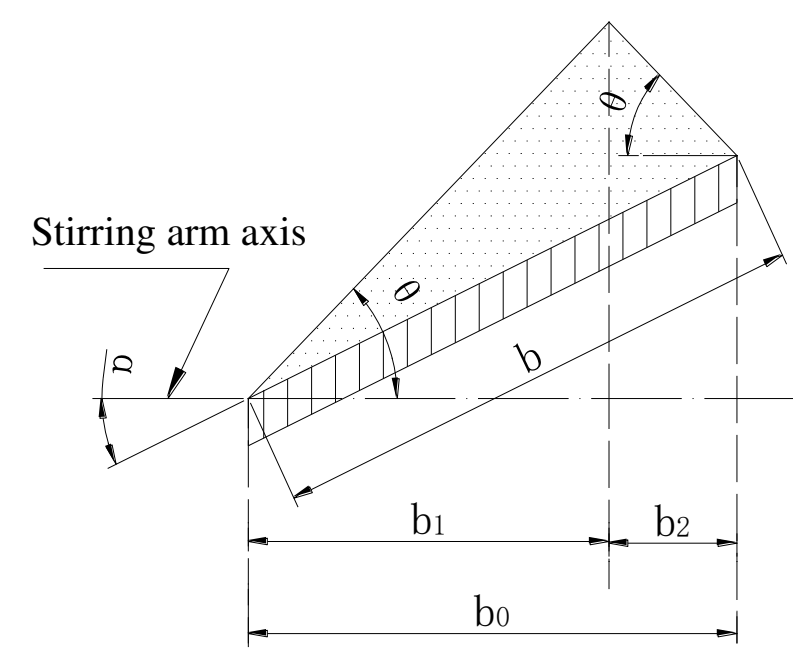

(b) Radial direction

FIGURE 3. Schematic diagram of material pile in front of blade.

127 The mixing speed coefficient is used to describe the axial and circumferential movement of the mixture, as shown in (1)

128 [10]. Where $K$ is Mixing speed coefficient, $K_{\mathrm{a}}$ is axial velocity coefficient, $K_{\mathrm{c}}$ is circumferential velocity coefficient,

$129 W_{0}$ is the projection length of the blade on the horizontal line; $W_{1}, W_{2}$ are the projection length of the two edges of 130 the blade on the horizontal line; 


$$
\left\{\begin{array}{l}
K_{\mathrm{a}}=\left(W_{1}-W_{2}\right) / W_{0}=\tan (\beta-\gamma) / \tan \theta \\
K_{\mathrm{c}}=S_{1} / S_{2}=\cos ^{2}(\beta-\gamma)-\cot ^{2} \theta \sin ^{2}(\beta-\gamma) \\
\left.K=K_{\mathrm{a}} K_{\mathrm{c}}=[\tan (\beta-\gamma) / \tan \theta] \mathrm{g} \cos ^{2}(\beta-\gamma)-\cot ^{2} \theta \sin ^{2}(\beta-\gamma)\right]
\end{array}\right.
$$

132 In order to maximize the axial and circumferential velocity of the mixture, if $K^{\prime}(\beta)=0$, we can get:

$133 K^{\prime}(\beta)=\tan ^{2} \theta-2 \sec ^{2} \theta \sin ^{2}(\beta-\gamma)-\tan ^{2}(\beta-\gamma)=0$.

134 From $\theta=55^{\circ} \sim 70^{\circ}, \gamma=2^{\circ} \sim 6^{\circ}, \beta=33.54^{\circ} \sim 45.36^{\circ}$.

135 According to the calculation method of axial installation angle, the range of blade radial installation angle is: $136 \alpha=31.54^{\circ} \sim 39.36^{\circ}$.

\subsection{Rotation speed of inner cylinder}

138 The rotation speed of the inner cylinder is controlled within a certain range, and the mixture will fall from the blade 139 when it reaches a certain height.The force analysis of the mixing unit on the blade is shown in Fig.4. If the mixture 140 is in the self falling state, the sliding force of material unit should overcome the centrifugal force and friction force. 141 As shown in Fig. 4,Centrifugal force $F_{c}$ can be divided into component force $F_{a}$ and component force $F_{b}$, $142 F_{a}$ is parallel to the blade and $F_{b}$ is perpendicular to the blade; Similarly, gravity $G$ can be divided into 143 component force $G_{1}$ and component force $G_{2}, G_{1}$ is parallel to the blade and $G_{2}$ is perpendicular to the blade. 144 Before the inner cylinder speed reaches the critical speed, the conditions for the mixture to meet the self falling are 145 as follows:

146

$$
\begin{aligned}
& F_{a}+f \leq G_{1} \\
& \left\{\begin{array}{l}
F_{a}=F_{c} \cos \alpha \\
F_{c}=m \omega^{2} R=\frac{m \pi^{2} n^{2} R}{30^{2}} \\
G_{1}=m g \sin (\alpha+\delta) \\
f=\mu\left[G_{2}+F_{b}\right] \\
G_{2}=m g \cos (\beta-\gamma) \cos (\alpha+\delta) \\
F_{\mathrm{b}}=F_{c} \sin \alpha
\end{array}\right.
\end{aligned}
$$

148 Where $\delta$ is Material glide angle, $R$ is blade end rotation radius, $g$ is gravitational acceleration. $\gamma=2^{\circ} \sim 6^{\circ}$, 
$\beta=30^{\circ} \sim 46^{\circ}, \alpha=0^{\circ} \sim 45^{\circ}, \delta=42^{\circ} \sim 75^{\circ}[11]$.

Take (3) into (2) to calculate:

151

$$
n \leq \frac{30}{\pi} \sqrt{\frac{g \sin (\alpha+\delta)-\mu g \cos (\beta-\gamma) \cos (\alpha+\delta)}{R(\cos \alpha+\mu \sin \alpha)}}
$$

152 Substituting the above parameters into (4), the critical speed of the drum is $13.4 \mathrm{r} / \mathrm{min}$. According to the speed 153 requirements, the primary drum speed is 6-10 $\mathrm{r} / \mathrm{min}$.

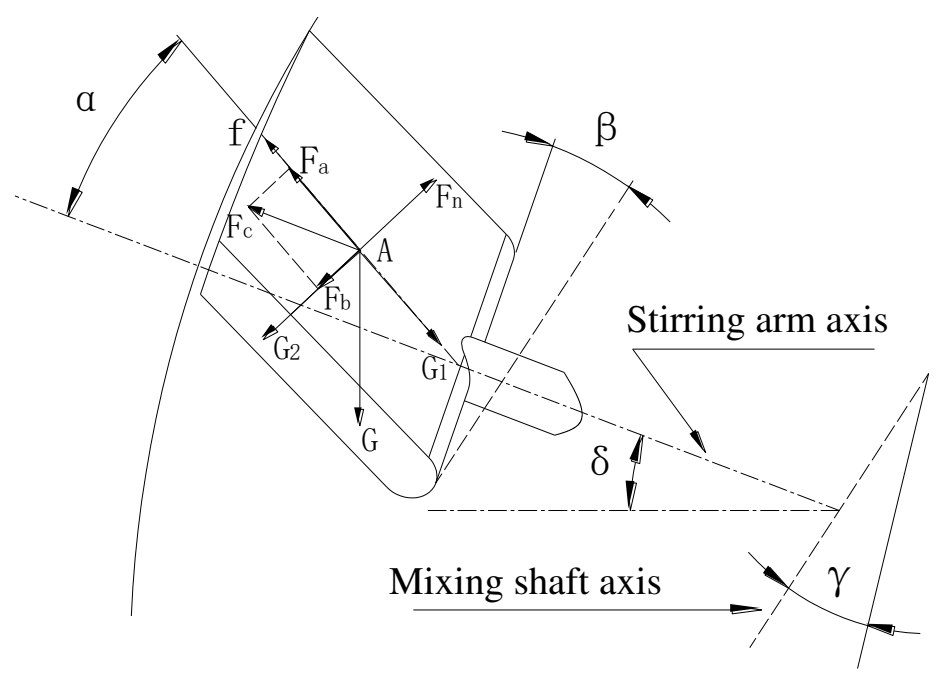

FIGURE 4. Force analysis of material unit.

\subsection{Phase angle of mixing arm}

157 Under the action of gravity, the particles of the mixture do parabolic motion at a certain initial speed. The initial

158 velocity $V_{0}$ is composed of the relative velocity $V_{\mathrm{r}}$ and the implicated velocity $V_{\omega}$, that is $V_{0}=V_{\mathrm{r}}+V_{\omega} . V_{\omega}$ is the 159 linear speed of rotation of the inner cylinder, $V_{\mathrm{r}}$ is the sliding speed of particles on the stacking surface of the blade.

160 Because $V_{\mathrm{r}}=V_{\omega}$, therefore, $V_{\omega}$ is taken as the initial velocity of scattering[12][13]. 


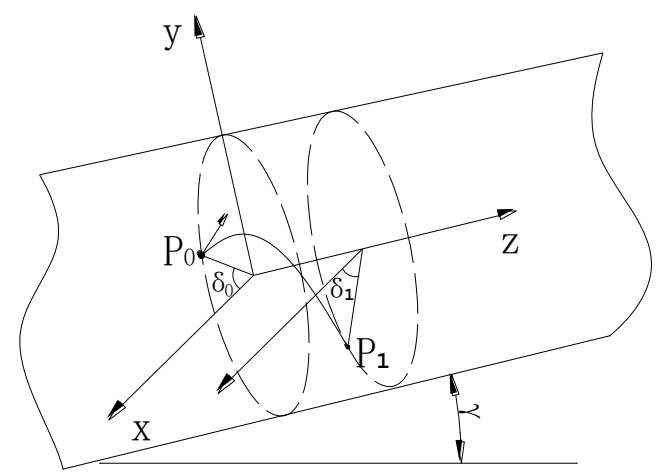

FIGURE 5. Schematic diagram of material throwing.

163 Established the coordinate system as shown in Figure 5. The $\mathrm{X}$ axis is parallel to the ground, and the $\mathrm{Z}$ axis coincides 164 with the mixing axis.The particle is thrown out at the initial speed from point $P_{0}$ (corresponding position angle $\delta_{0}$ ) 165 and falls to point $P_{1}$ (corresponding position angle $\delta_{1}$ ) on the cylinder wall, its movement equation in the mixing 166 drum is shown in (3).

$$
\left\{\begin{array}{l}
m \mathrm{~d}^{2} x / \mathrm{d} t^{2}=0 \\
m \mathrm{~d}^{2} y / \mathrm{d} t^{2}=-m g \cos \gamma \\
m \mathrm{~d}^{2} z / \mathrm{d} t^{2}=-m g \sin \gamma
\end{array}\right.
$$

Where $\mathrm{X}, \mathrm{y}$ and $\mathrm{Z}$ are the projections of material particles on the $\mathrm{X}, \mathrm{y}$ and $\mathrm{Z}$ axes; t is the time the particle moving 169 from point $P_{0}$ to point $P_{1}$. According to the initial boundary condition, when $\mathrm{t}=0$, take the approximate values for

$170 \mathrm{X}_{0}, \mathrm{Y}_{0}$ and $\mathrm{Z}_{0}$, Differential equation of motion is shown in (4).

$171\left\{\begin{array}{l}x=-R \omega t \sin \left(\alpha+\delta_{0}\right)+R \cos \delta_{0} \\ y=-(1 / 2) g t^{2} \cos \gamma+R \omega t \cos \beta \cos \left(\alpha+\delta_{0}\right)+R \sin \delta_{0} \\ z=-(1 / 2) g t^{2} \sin \gamma+R \omega t \sin \beta \cos \left(\alpha+\delta_{0}\right)\end{array}\right.$

(4) and the inner wall of the outer cylinder,

173 corresponding to the coordinate system shown in Figure 7, the cylinder equation is $x^{2}+y^{2}=R^{2}$. Thus, the time $t_{p}$

174 is particle movement from $P_{0}$ to $P_{1}$ is obtained. The positions $x_{1}$ and $y_{1}$ of particles along the $x$ and $y$

175 directions can be expressed as:

$176\left\{\begin{array}{l}x_{1}=-R \omega t_{p} \sin \left(\alpha+\delta_{0}\right)+R \cos \delta_{0} \\ y_{1}=-(1 / 2) g t_{p}^{2} \cos \gamma+R \omega t_{p} \cos \beta \cos \left(\alpha+\delta_{0}\right)+R \sin \delta_{0}\end{array}\right.$ 
The projection of the trajectory of the mixture on the XOY plane is shown in Fig.6.

178

179

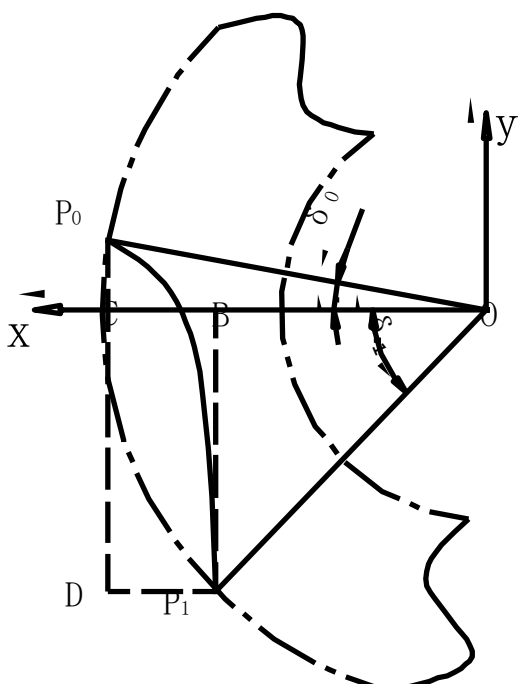

(a) Below the $\mathrm{X}$ axis

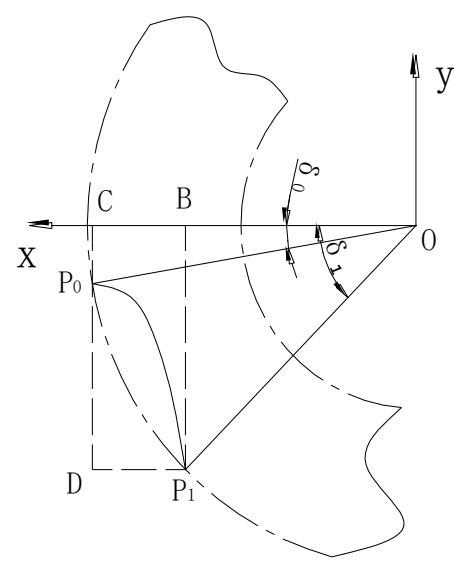

(b) Above the $\mathrm{X}$ axis

FIGURE 6. Projection diagram of materials thrown on $x O y$ plane.

After the particles fall to point a, they roll down along the inner wall of the outer cylinder,In order to reduce the segregation of the mixture, the phase angle between adjacent blades shall meet the following relationship:the spray position is above the $\mathrm{X}$-axis, $\varphi \leqslant \delta_{1}+\delta_{0}$; the spray position is under the $\mathrm{X}$-axis, $\varphi \leqslant \delta_{1}-\delta_{0}$, where $\tan \delta_{1}=\left|y_{1}\right| /\left|x_{1}\right|, \varphi \leqslant 67.3^{\circ}$.

\section{Simulation analysis}

\subsection{Discrete element method(DEM)Contact model}


189 The simulation model is established based on DEM, the contact relationship of DEM generally includes particle to 190 particle and particle to geometry, as shown in Figure 7. The displacement change of particles in contact is shown in 191 Figure 8, Particle $\mathrm{i}$ is in contact with particle $\mathrm{j}$ at point $\mathrm{C}$, dotted line is the initial contact position, a is the tangent 192 overlap, $\delta$ is the normal overlap.

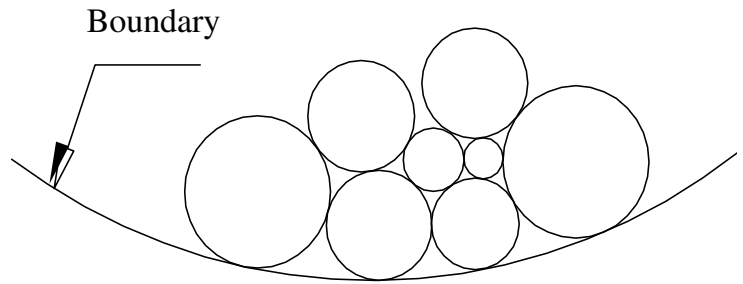

FIGURE 7. Particle contact diagram.

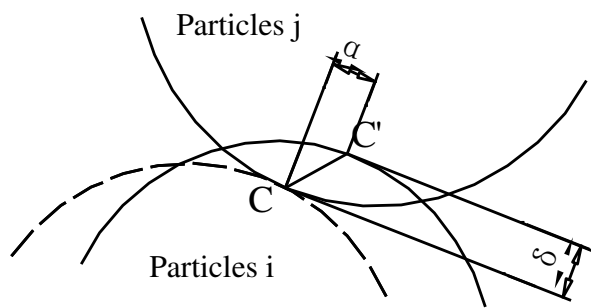

FIGURE 8. Schematic diagram of particle contact displacement.

The vibration equation can be used to express the contact problem of particle model in DEM. The contact relationship of particles is represented by vibration model as shown in Fig.9. Where a) is normal vibration model, b) is tangent vibration model and c) is sliding model.

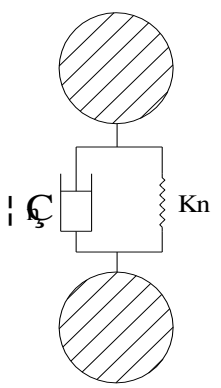

a)

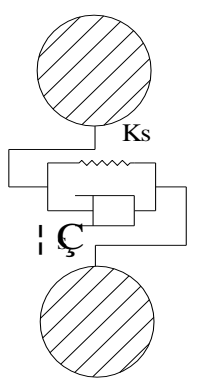

b)

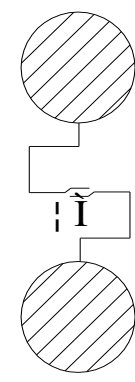

c)

FIGURE 9. Vibration model.

The vibration motions of particles are disintegrated into the normal and tangential directions in the process of 
slide equation, the third is tangential rolling equation.

$$
\left\{\begin{array}{l}
m_{1,2} d^{2} u_{n} / d t^{2}+c_{n} d u_{n} / d t+K_{n} u_{n}=F_{n} \\
m_{1,2} d^{2} u_{s} / d t^{2}+c_{s} d u_{s} / d t+K_{s} u_{s}=F_{s} \\
I_{1,2} d^{2} \theta / d t^{2}+\left(c_{s} d u_{s} / d t+K_{s} u_{s}\right) s=M
\end{array}\right.
$$

207 Where $m_{1,2}$ is the equivalent mass of particles; $I_{1,2}$ is the equivalent moment of inertia; $\mathrm{r}$ is the revolving 208 radius; unis the relative displacement normally, and us is the tangential one; $\theta$ denotes rotational angle for itself, $F_{n}$ is

209 the normal components of particles acted on by outside force, $F_{s}$ is the tangential one; $M$ is the external moment of

210 particles, $K_{n}$ is the normal elastic coefficient in contact model, $K_{s}$ is the tangential one; $c_{n}$ is the normal damping

211 coefficient; $c_{s}$ is the tangential one.

212 The friction force between contacting particles has an effect on the tangential sliding and rolling of particles.

213 Through the sliding model, the limiting conditions of tangential sliding and rolling can be obtained as shown in 214 equation (6):

$F_{s}=\mu K_{n} u_{n} \operatorname{sgn}\left[K_{s}\left(u_{s}+d \theta / 2\right)\right]$

216 Where ${ }^{\mu}$ is the friction coefficient, $\operatorname{sgn}(x)=\left\{\begin{array}{l}1, \quad x \geq 0 \\ -1, \quad x<0\end{array}\right.$.

\subsection{Simulation model of double drum regenerative mixing plant}

218 Simulation model of double drum regeneration mixing equipment is established by EDEM software, as shown in 219 Fig.10.In order to improve the simulation speed, the aggregate in the mixture is simplified as a single spherical particle 220 model. Three kinds of aggregate with different particle size range are used to simulate the mixture. The particle size 221 range is $2.36-4.75 \mathrm{~mm}, 4.75-9.5 \mathrm{~mm}$, and 9.5-19 mm, respectively. Named aggregate 1, aggregate 2, and aggregate 3. According to the production efficiency and gradation, the production rate of each particle factory is 1.51 , aggregate 14.73 , and aggregate $20.21 \mathrm{~kg} / \mathrm{s}$. 


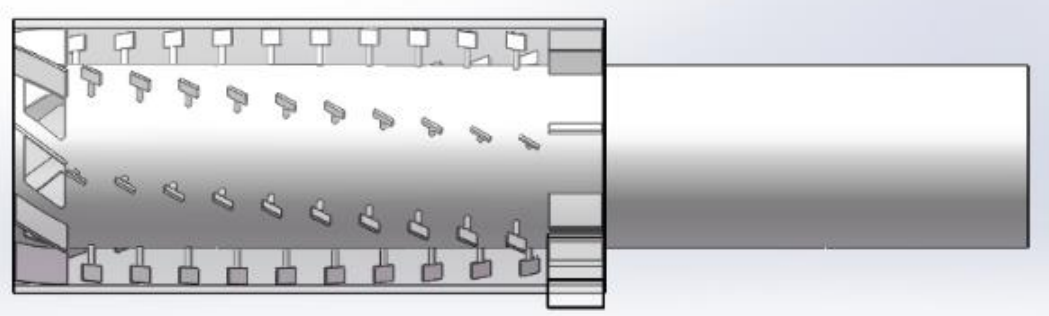

FIGURE 10. Simulation model of double drum regeneration mixing equipment.

226 The contact forces between asphalt and mineral aggregate, between mineral aggregate and mineral aggregate 227 covered with asphalt, and between mineral aggregate and mixing plant are complex, including inter molecular Van der

228 Waals force, acid-base force based on chemical reaction, meshing friction force, etc. in order to simulate the adhesion 229 of asphalt, Hertz Mindlin with JKR cohesion contact model in EDEM software was selected.The intrinsic parameters 230 and contact parameters of mixing device and material particles are shown in Table 1 and Table 2 . Where $\mu$ is 231 Poisson's ratio; E is shear modulus; $\rho$ is the density; $e$ is the recovery coefficient; $f_{j}$ is static friction coefficient,

$232 f_{d}$ is dynamic friction coefficient.

TABLE 1. Intrinsic parameters of mixing device and mixture.

\begin{tabular}{cccc}
\hline material & $\mu$ & $E(\mathrm{GPa})$ & $\rho\left(\mathrm{kg} \bullet \mathrm{m}^{-3}\right)$ \\
\hline steel & 0.30 & 70 & 7850 \\
aggregate & 0.25 & 23 & 2850 \\
\hline
\end{tabular}

TABLE 2. Contact parameters of mixing device and material particles.

\begin{tabular}{cccc}
\hline Contact relationship & $e$ & $f_{j}$ & $f_{d}$ \\
\hline Steel -aggregate & 0.10 & 0.6 & 0.24 \\
Aggregate-aggregate & 0.06 & 0.8 & 0.32 \\
\hline
\end{tabular}

235 3. Analysis of factors affecting mixing uniformity (Single factor)

\subsection{Influence of drum speed on mixing uniformity}

237 Let $\beta=40^{\circ}, \alpha=36^{\circ}, \varphi=40^{\circ}, \gamma=4^{\circ}, \mathrm{n}$ is $6 \mathrm{r} / \mathrm{min}, 7 \mathrm{r} / \mathrm{min}, 8 \mathrm{r} / \mathrm{min}, 9 \mathrm{r} / \mathrm{min}$, and $10 \mathrm{r} / \mathrm{min}$ respectively. After 238 the material flow is stable, the particle distribution of the mixture at different speed is as shown in Fig.12. 


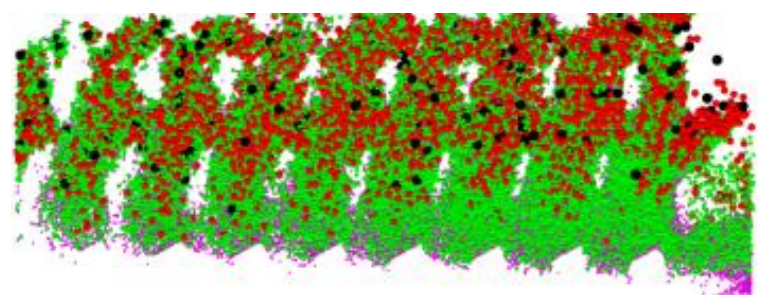

(a) $\mathrm{n}=6 \mathrm{r} / \mathrm{min}$

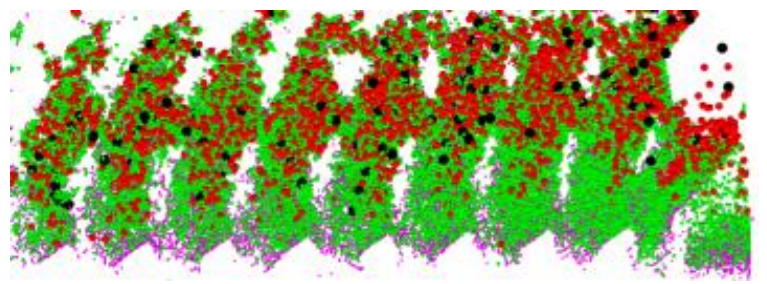

(b) $\mathrm{n}=7 \mathrm{r} / \mathrm{min}$

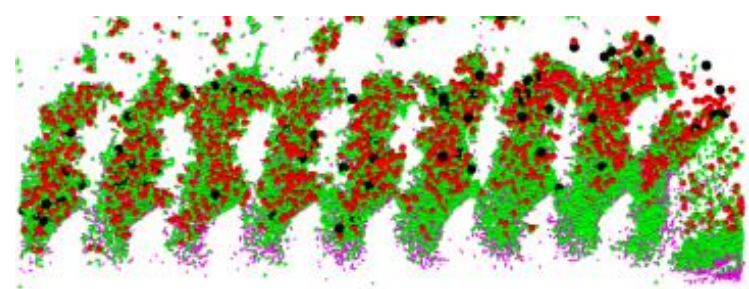

(c) $n=8 r / m i n$

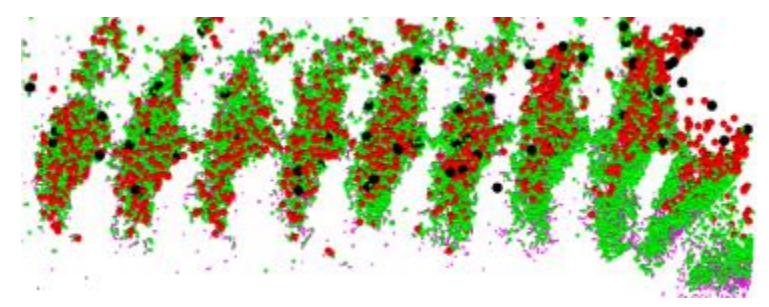

(d) $\mathrm{n}=9 \mathrm{r} / \mathrm{min}$

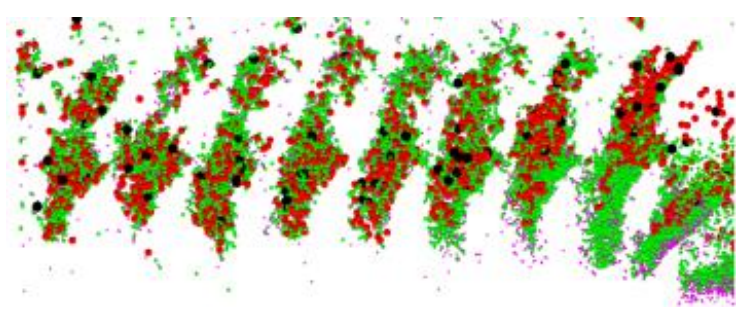

(e) $n=10 r / m i n$

FIGURE 11. Mixture distribution at different speeds.

250 In the mixture distribution diagram shown in Figure 11, the right side is the feed port and the left side is the 251 discharge port. Due to the setting of the particle factory, small particles (green and pink particles in the figure) are 
252 distributed in the bottom layer, that is, the mixture enters the mixing chamber in the state of segregation. It can be seen 253 from Figure 11 that the segregation of the mixture is gradually improved along the axial direction of the mixing 254 chamber, that is, the extension of the mixing time is conducive to the improvement of the mixture uniformity. As 255 shown in Fig.11 (a) and (b), the aggregate segregation is serious and almost runs through the whole mixing chamber. 256 With the increase of rotation speed, the mixture uniformity is improved to some extent as shown in Fig.11 (c). When $n$ is 9r/ min and 10r/ min, as shown in Fig.11(d) and (e), there is almost no obvious segregation in the middle of the mixing chamber and after.

259 The average velocity of the particles in the mixing chamber at different speeds is shown in Fig.13.It can be seen from 260 Fig.12 that after the material flow is stable, the higher the drum speed is, the greater the average movement speed of the 261 mixture particles is.

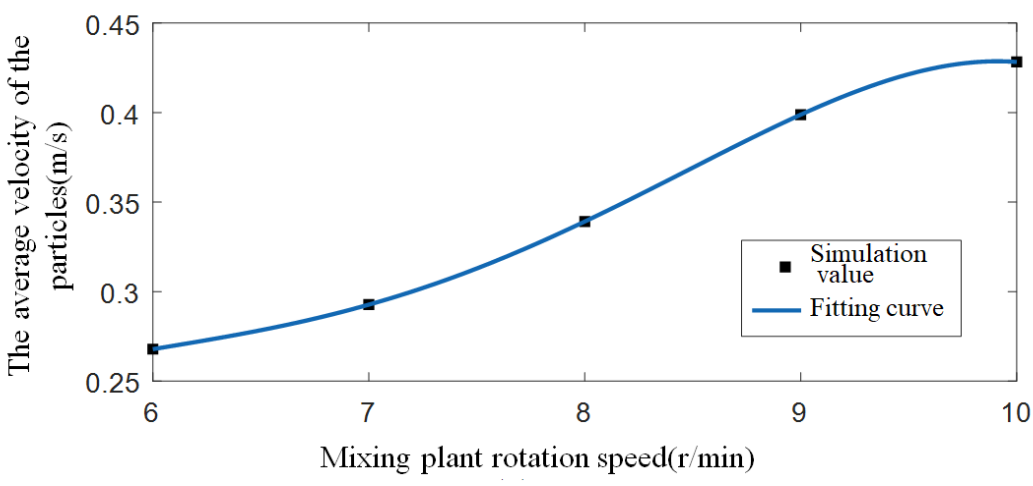

FIGURE 12. Average particle velocity at different speed.

According to the analysis of Fig11 and Fig.12, when the feed rate of the feed port is constant, the slow speed of the drum is not conducive to the movement of the mixture particles, resulting in a relatively large filling ratio of the mixture in the mixing drum, as shown in Fig.11 (a) and (b). The wrapping of the thick material layer limits the large267 scale cross movement of the material particles, and the slow rotation speed of the roller itself reduces the intensity of the mixture movement, and the segregation is serious when the final rotation speed is slow. The distribution data of three kinds of aggregate at the outlet are extracted respectively, the relationship between the dispersion coefficient of aggregate and drum speed is shown in Fig.13. 


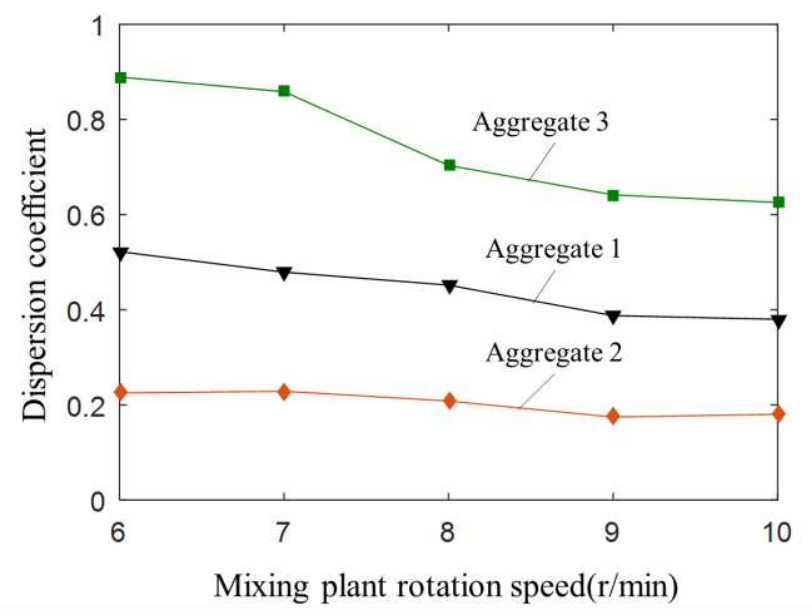

FIGURE 13. The relationship between the dispersion coefficient of aggregate and drum speed.

273 As shown in Figure 13, the drum speed has a great influence on the mixing uniformity of the mixture. When the 274 rotating speed of drum increases from $6 \mathrm{r} / \mathrm{min}$ to $9 \mathrm{r} / \mathrm{min}$, the dispersion coefficients of three kinds of aggregate decrease, 275 and the dispersion coefficients of aggregate 1 and aggregate 3 decrease obviously.Because aggregate 1 and aggregate 3 276 are relatively fine and coarse particles, and the number of particles is relatively small, it is easy to produce 277 segregation. When the rotating speed of the drum is low, the distribution of particles is less disturbed. With the increase 278 of the rotating speed of the drum, the aggregate throwing increases correspondingly, the large-scale cross movement 279 among particles becomes more intense, and the renewal frequency of particle position increases.Because the number of 280 particles in aggregate 2 is relatively large and the particle size is moderate, its particle distribution has strong anti281 interference ability and small fluctuation range of dispersion coefficient. When the drum speed changes from $9 \mathrm{r} / \mathrm{min}$ to $28210 \mathrm{r} / \mathrm{min}$, the decrease range of the dispersion coefficient of aggregate 1 and aggregate 3 becomes smaller, and the 283 dispersion coefficient of aggregate 2 increases slightly, that is to say, the influence of drum speed on the uniformity of 284 aggregate is nonlinear. When the rotating speed of the drum reaches a certain value, the mixture distribution tends to be 285 stable, and further increasing the rotating speed will not have a great positive effect on the improvement of mixing 286 uniformity.

\subsection{Influence of drum inclination on mixing uniformity}

Let $\beta=40^{\circ}, \alpha=36^{\circ}, \varphi=40^{\circ}, n=8 \mathrm{r} / \mathrm{min}, \gamma$ is $2^{\circ}, 3^{\circ}, 4^{\circ}, 5^{\circ}, 6^{\circ}$, respectively. The relationship between the dispersion coefficient of aggregate and the inclination of drum is shown in Fig.14. 


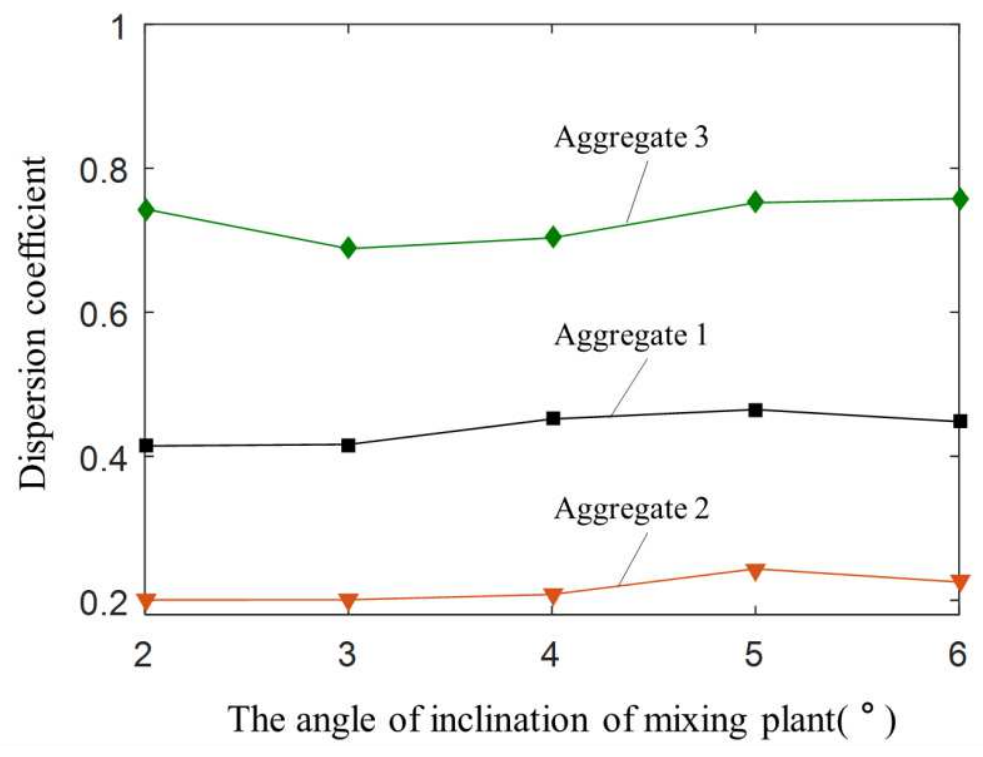

FIGURE 14. The relationship between the dispersion coefficient of aggregate and the angle of inclination of drum.

As shown in Figure 14, with the change of drum inclination, the dispersion coefficient of aggregate 1 and aggregate

2932 fluctuates less, and the dispersion coefficient of aggregate 3 fluctuates relatively more, but it is also controlled within 294 the range of 0.07 , indicating that the change of drum inclination has less influence on the uniformity of 295 mixture.Theoretically, increasing the inclination of the drum can prolong the retention time of the mixture in the mixing drum and increase the mixing times. However, as shown in Fig.15, the greater the inclination of the drum is, the greater the segregation of the mixture is.Collect the number of mixture particles in the middle area of the mixing drum.

298 The relationship between the number of mixture particles and the inclination of the drum is shown in Fig.15.

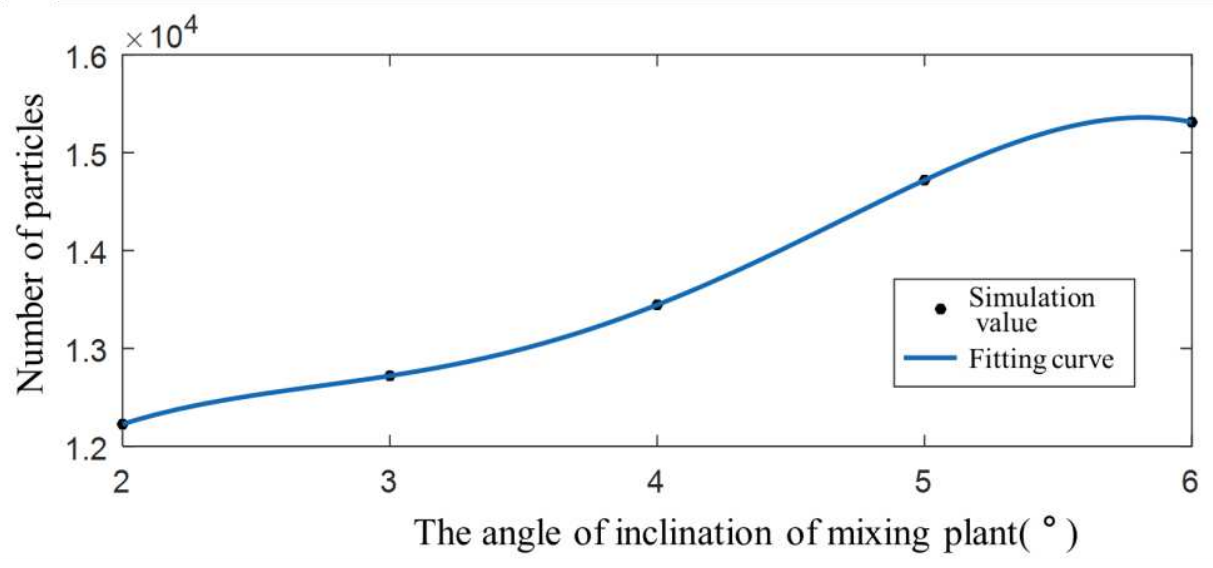

FIGURE 15. The number of particles in the middle of the mixing drum with different inclination.

301 As shown in Figure 15, the greater the inclination of the drum, the more particles of the mixture retained in the 
302 drum.Due to the constant feed rate of the feed port, the increase of the number of particles in the mixing drum indicates

303 that the axial movement speed is weakened and the retention time of the mixture is prolonged.

304 The feed rate of particle factory is reduced by $30 \%$, and other parameters remain unchanged. The uniformity of 305 mixture is analyzed when the inclination of roller is $6^{\circ}$.

306 The dispersion coefficients of aggregate 1,2 and 3 are $0.427,0.184$ and 0.683 respectively, which are lower than 307 before the feed rate is reduced.It shows that the filling ratio of the mixing chamber is high when the inclination angle 308 of the drum is $6^{\circ}$ without the decrease of the feeding rate. It can be concluded that increasing the inclination of the 309 drum can prolong the mixing time of the mixture. However, the retained mixture is easy to cause a large filling ratio in 310 the mixing drum, which is not conducive to mixing.

311 The dispersion coefficient of the three aggregates at the drum inclination angle is $4^{\circ}$ and the rotation speed is $9 \mathrm{r} / \mathrm{min}$ 312 is smaller than that of the three aggregates at the drum inclination angle is $2^{\circ}$ and the rotation speed is $8 \mathrm{r} / \mathrm{min}$. Therefore, 313 in order to solve the problem of the increase of the filling ratio of the mixing drum caused by the increase of the 314 inclination angle of the drum, the speed of the drum can be properly increased without reducing the productivity.

\subsection{Influence of blade axial installation angle on mixing uniformity}

316 Let $\alpha=36^{\circ}, \varphi=40^{\circ}, \gamma=4^{\circ}, n=8 \mathrm{r} / \mathrm{min}, \beta=31^{\circ}, 34^{\circ}, 37^{\circ}, 40^{\circ}, 43^{\circ}, 46^{\circ}$, respectively. The relationship between the 317 dispersion coefficient of aggregate and blade axial installation angle is shown in Fig.16.

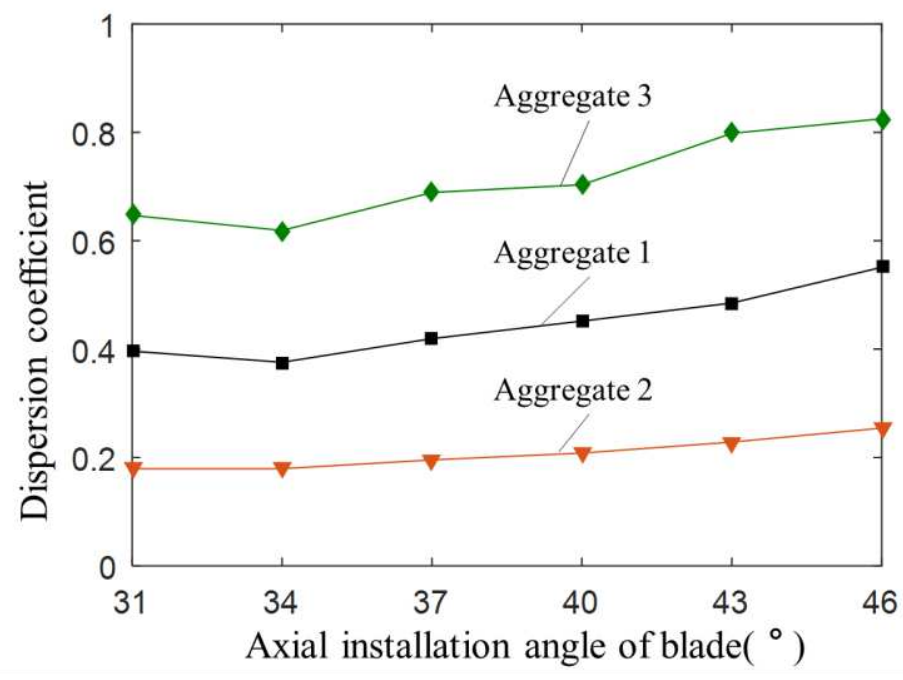

FIGURE 16. The relationship between the dispersion coefficient of aggregate and blade axial installation angle

As shown in Figure 16, the axial installation angle of blade has great influence on the mixing uniformity. When the 
321 axial installation angle of the blade increases from $34^{\circ}$ to $46^{\circ}$, the dispersion coefficients of the three aggregates all 322 increase. When the axial installation angle of blade decreases from $34^{\circ}$ to $31^{\circ}$, the dispersion coefficients of aggregate 3231 and aggregate 3 increase slightly. In general, when $\beta=34^{\circ}$, the uniformity of the mixture is better.

324 The axial installation angle affects the intensity of axial and circumferential movement of the mixture, and then 325 affects the mixing uniformity. In order to analyze the influence of blade axial installation angle on aggregate movement speed. The average velocities of all particles moving along the axial and circumferential directions at different axial installation angles were collected, as shown in Fig.17.

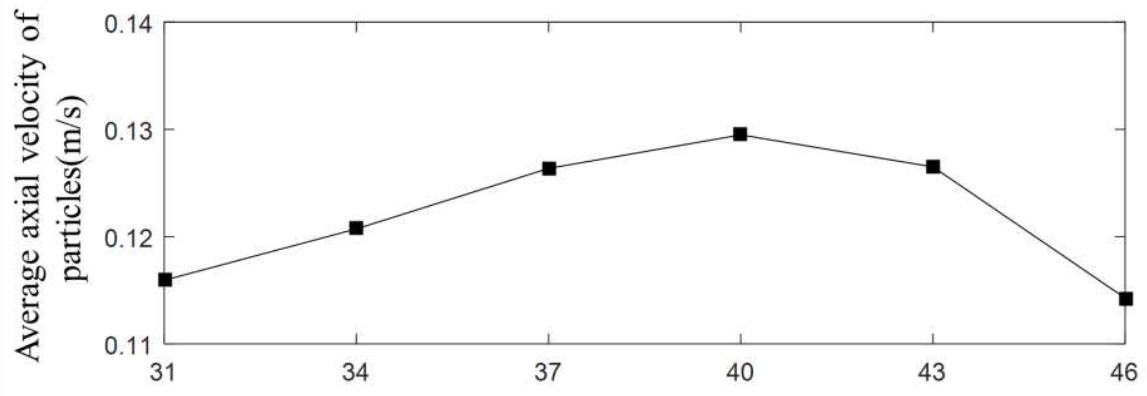

Axial installation angle of blade $\left({ }^{\circ}\right)$

(a)

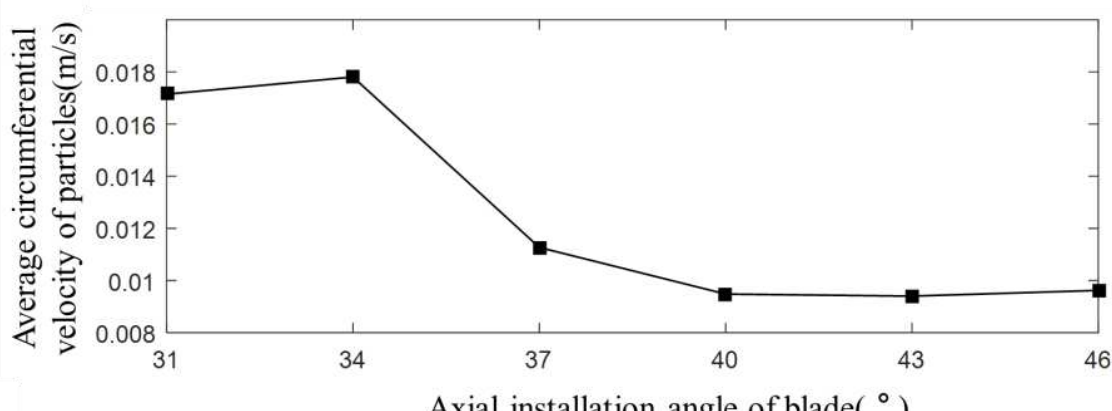

FIGURE 17. The average velocity of particles in axial and circumferential directions with different axial installation angles.

As shown in Fig.17, the axial installation angle of blade increases from $31^{\circ}$ to $46^{\circ}$, the average axial velocity of the particles increases first and then decreases, and the maximum value is obtained at $\beta=40^{\circ}$.The average

335 circumferential velocity of the particles in the mixture reaches the maximum value when $\beta=34^{\circ}$, and decreases with the increase of the axial installation angle of the blades. In combination with figure 16 and figure 17 , when $\beta=34^{\circ}$, 
337 the circumferential movement of the mixture is sufficient, which is conducive to the mixing of aggregates; the axial

338 movement speed of the mixture is slow, which is conducive to the extension of mixing time.

339 The feed rate of particle plant is reduced by $30 \%$, and other parameters are unchanged. The uniformity of mixture is

340 analyzed when $\beta=31^{\circ}$.The dispersion coefficients of aggregate 1,2 and 3 are $0.363 、 0.145$ and 0.626 respectively,

341 which are lower than before the feed rate is reduced.It shows that the filling ratio of the mixing drum is high when

$342 \beta=31^{\circ}$ without the decrease of the feeding rate. As shown in Fig.17, compared with $\beta=34^{\circ}$, when $\beta=31^{\circ}$, the

343 axial movement speed of the mixture is slower, and the filling ratio of the mixing drum is higher, which is not 344 conducive to the cross movement between particles. The circumferential velocity of the mixture is decreased, and the 345 particle throwing is weakened. Therefore, the axial installation angle should take into account the axial and 346 circumferential movement of the mixture.

\subsection{Influence of phase angle of mixing arm on mixing uniformity}

348 Let $\beta=40^{\circ}, \alpha=36^{\circ}, \gamma=4^{\circ}, n=8 \mathrm{r} / \mathrm{min}, \quad \varphi$ is $20^{\circ}, 30^{\circ}, 40^{\circ}, 50^{\circ}$ and $60^{\circ}$, respectively. The relationship 349 between the dispersion coefficient of aggregate and phase angle of mixing arm is shown in Fig.18.(The relationship 350 between $C_{v}$ and $\varphi$ as shown in Fig.18)

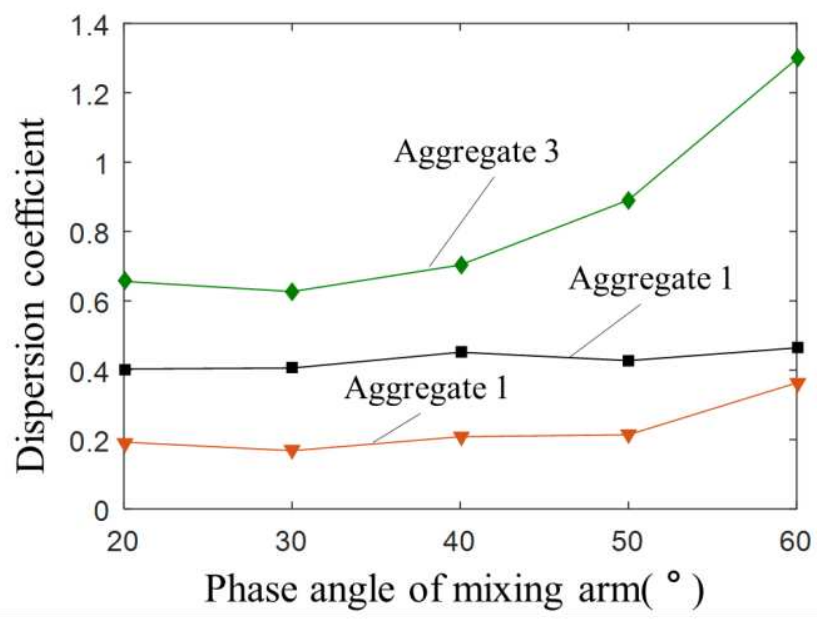

FIGURE 18. The relationship between the dispersion coefficient of aggregate and phase angle of mixing arm (The relationship between $\mathrm{C}_{\mathrm{v}}$ and $\varphi$ ).

As shown in Fig.18,the dispersion coefficient of aggregate 1 changes little, and the dispersion coefficients of aggregate 2 and aggregate 3 vary greatly. When the phase angle of the mixing arm is $30^{\circ}$, the dispersion coefficients of 
aggregate 2 and aggregate 3 are the minimum; When the phase angle of mixing arm increases from $30^{\circ}$ to $60^{\circ}$, the dispersion coefficient of aggregate 2 and aggregate 3 increases gradually, and the dispersion coefficient of aggregate 3 increases exponentially. It shows that the phase angle of the mixing arm has a significant impact on the uniformity of large particles in the mixture, and the large phase angle is unfavorable to the mixing of coarse aggregate.The mixing effect diagram of different mixing arm phase angle is shown in Figure 19.
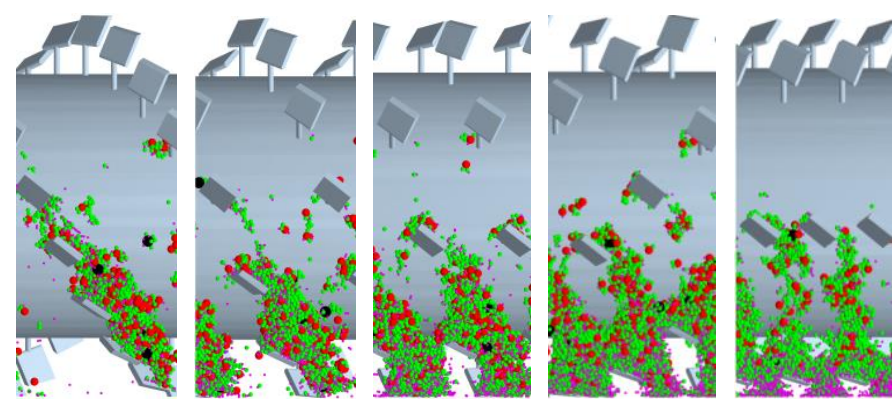

a) $\varphi=20^{\circ}$ b) $\varphi=30^{\circ}$ c) $\varphi=40^{\circ}$ d) $\varphi=50^{\circ}$ e) $\varphi=60^{\circ}$

FIGURE 19. The mixing effect diagram of different mixing arm phase angle.

As shown in Fig.19, the phase angle of the mixing arm increases, and the feeding cycle of the mixing equipment also increases. The increase of picking period will increase the rolling stroke of mixture, and the segregation of large particle will be intensified. Therefore, the phase angle of the mixing arm has a great influence on the uniformity of large particles. As shown in Fig. 19 (a), the phase angle of the mixing arm is too small, and the distance between adjacent blades is small. The mixing process is similar to the spiral conveying process, and the spraying of the mixture is low, which is not conducive to the mixing of the mixture.

369 Collect the number of particles in the middle section of the mixing drum,the relationship between the number of particles retained in the mixing drum and the phase angle of the mixing arm is shown in Fig.20.

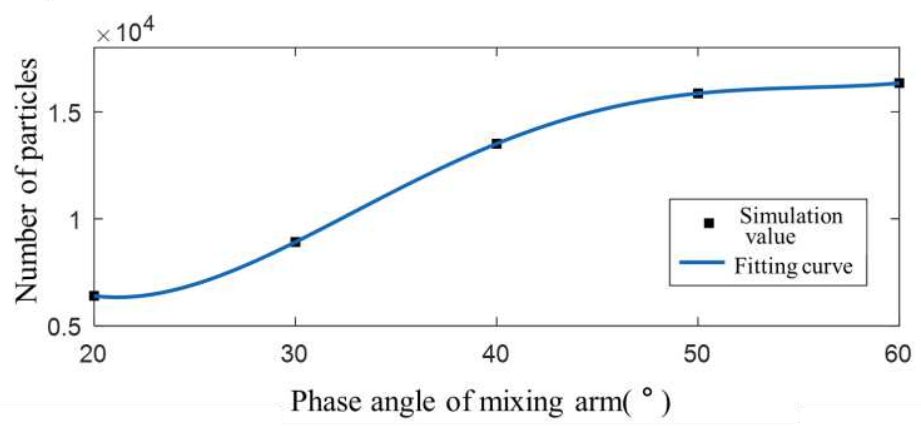


As shown in Fig.20, the larger the phase angle between the mixing arms is, the more the particles in the mixing drum are. It shows that with the increase of the phase angle, the velocity of the mixture slows down gradually. The increase of phase angle is easy to delay the mixing of the mixture, and increase the filling ratio of the mixing chamber.

The feed rate of particle plant is reduced by $30 \%$, and other parameters are unchanged. The uniformity of mixture is analyzed when the phase angle of the mixing arm is $60^{\circ}$. The dispersion coefficients of aggregate 1,2 and 3 are 0.451 , 0.316 and 1.038 , respectively, which are lower than before the feed rate is reduced. It shows that when the feed rate is constant and the phase angle of the mixing arm is $60^{\circ}$, the filling ratio of the mixing drum is on the high side. As shown in Fig.18 and Fig.20, when the phase angle of the mixing arm is $60^{\circ}$, the high filling ratio of the mixing drum is also the reason for the poor mixing uniformity of the mixture.

\subsection{Influence of blade radial installation angle on mixing uniformity}

Let $\beta=40^{\circ}, \varphi=40^{\circ}, \gamma=4^{\circ}, n=8 \mathrm{r} / \mathrm{min}, \quad \alpha$ is $32^{\circ}, 34^{\circ}, 36^{\circ}, 38^{\circ}$ and $40^{\circ}$ respectively. The relationship between the and $\alpha$ as shown in Fig.21).

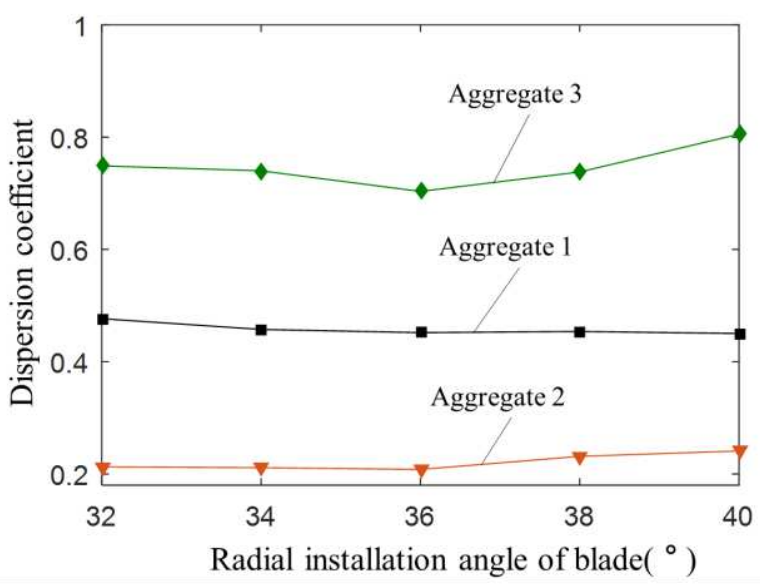

FIGURE 21. The relationship between the dispersion coefficient of aggregate and blade radial installation angle(The relationship between CV and a ).

As shown in Figure 21, the dispersion coefficient of aggregate 1 and aggregate 2 has little change. The dispersion coefficient of aggregate 3 is relatively large influenced by the radial installation angle of blade, but its fluctuation range is also less than 0.11. It shows that the radial installation angle of blade has little influence on the uniformity of mixture.

The radial installation angle of the blade can make the mixture separate from the inner wall of the outer cylinder, 
393 shown in Figure 21, the uniformity of aggregate 3 is greatly affected by the radial installation angle of blade. When the 394 radial installation angle of blade is $36^{\circ}$ and other parameters remain unchanged, the uniformity of aggregate is 395 compared when the phase angle of mixing arm is $60^{\circ}$ and $40^{\circ}$. The results show that the dispersion coefficients of 396 aggregate 1,2 and 3 are $0.464,0.363$ and 1.298 respectively when the phase angle is $60^{\circ}$, which are higher than that 397 when the phase angle is $40^{\circ}$.

398 As shown in Figure 22, the cross section of the mixing drum when the phase angle of the mixing arm is $40^{\circ}$.After the 399 mixture is thrown away from the previous blade and then lifted by the next blade, the distance of particles rolling down 400 the inner wall of the outer cylinder is shortened. It can be concluded that the setting of phase angle in the simulation test 401 of this section has the function of reducing the rolling segregation. Therefore, the dispersion coefficient of aggregate 3 402 has no obvious trend with the change of blade radial installation angle.

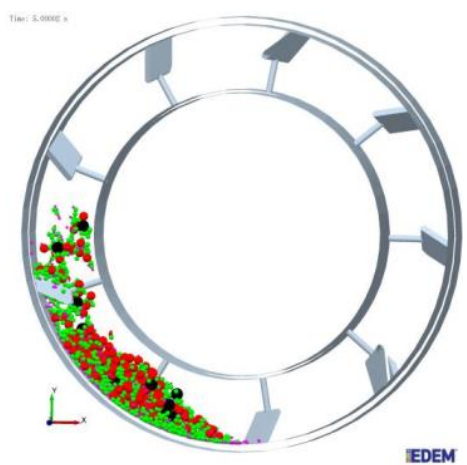

FIGURE 22. Sectional drawing of mixing drum.

405 In addition, the radial installation angle of the blade will also affect the movement speed of the mixture particles. In 406 order to study the influence of blade radial installation angle on the mixture moving speed, collect the average speed of 407 all particles, and get the average moving speed of particles under different radial installation angles as shown in Fig.23. 


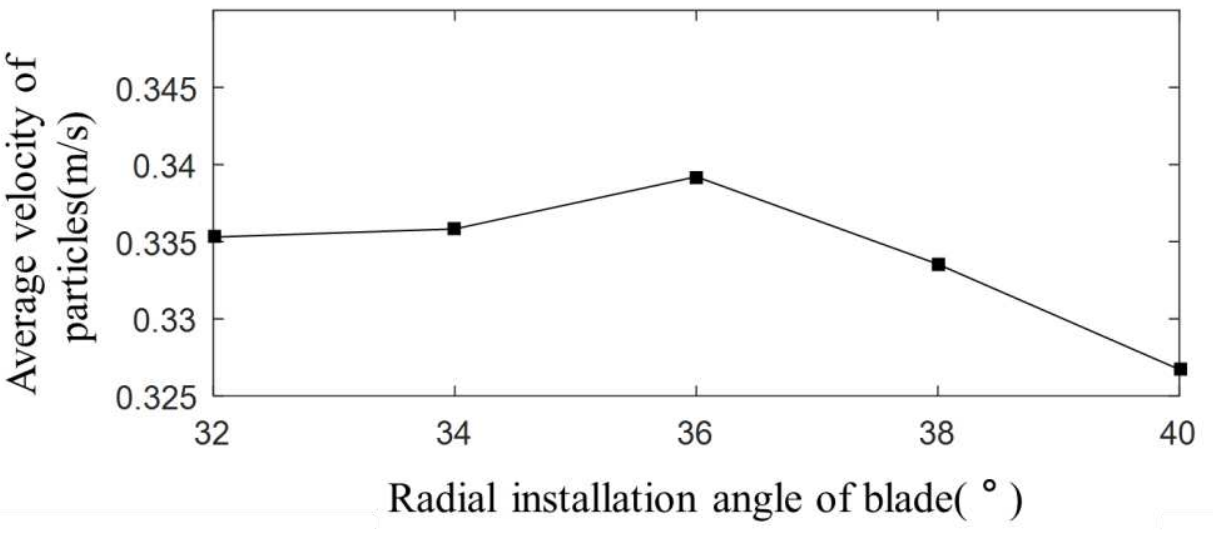

FIGURE 23. Change of particle average velocity with time under different radial installation angles.

As shown in Fig.24, the average velocity of particles has little change, that is, the radial installation angle of blade 411 has little influence on the velocity of mixture. According to Fig. 21 and Fig. 23, when the radial installation angle of 412 blade is $36^{\circ}$, the average velocity of particles in the mixture is relatively large, and the homogeneity of the mixture is 413 relatively well. When the radial installation angle of blade is $40^{\circ}$, the average velocity of particles is slow, which is not 414 conducive to the mixing of mixture.

\section{4.Response surface methodology(RSM) analysis}

416 The influence of each single factor on the mixing uniformity of the mixture was studied, in order to analyze the 417 interaction between various factors and solve the best parameters match, the response surface method is used for further 418 research.

\subsection{Simulation scheme design}

420 Referring to the design of the structural parameters and motion parameters of the double drum mixing equipment in the 421 previous paper, the value ranges of five factors are set as follows: the axial installation angle of the blade (A), the radial 422 installation angle of the blade (B), the phase angle of the mixing arm (C), the inclination angle of the drum (D) and the 423 rotation speed of the drum $(\mathrm{E})$, are respectively set as follows : $42434^{\circ} \leq A \leq 46^{\circ}, 32^{\circ} \leq B \leq 40^{\circ}, 20^{\circ} \leq C \leq 60^{\circ}, 2^{\circ} \leq D \leq 6^{\circ}$, and $6 r / \min \leq E \leq 10 \mathrm{r} / \mathrm{min}$.

425 Taking A, B, C, D, E as the influencing factors and the discrete coefficient of aggregate as the response value, 426 according to the design method of response surface experiment, the simulation scheme of five factors and three levels 
427 is designed.As shown in table 3.

TABLE 3. Influencing factors and level value.

\begin{tabular}{llll}
\hline & \multicolumn{4}{c}{ level value } \\
\cline { 2 - 4 } Influencing factors & -1 & 0 & 1 \\
\hline axial installation angle $(\mathrm{A}) /{ }^{\circ}$ & 34 & 40 & 46 \\
radial installation angle $\quad(\mathrm{B}) / /^{\circ}$ & 32 & 36 & 40 \\
phase angle of the mixing arm (C) $/{ }^{\circ}$ & 20 & 40 & 60 \\
inclination angle of the drum (D) $/{ }^{\circ}$ & 2 & 4 & 6 \\
rotation speed of the drum (E) $/ \mathrm{r} \cdot \mathrm{min}^{-1}$ & 6 & 8 & 10 \\
\hline
\end{tabular}

\section{$429 \quad 4.2$ Simulation results and analysis}

430 According to the range of influence factors in Table 3,the simulation scheme and results obtained by Box Behnken 431 design test method as shown in Table 4:

TABLE 4. Simulation scheme and results.

\begin{tabular}{|c|c|c|c|c|c|c|c|c|}
\hline \multirow[b]{2}{*}{$\begin{array}{l}\text { num } \\
\text { ber }\end{array}$} & \multicolumn{5}{|c|}{ simulation scheme } & \multicolumn{3}{|c|}{ discrete coefficient } \\
\hline & $\begin{array}{c}\text { axial } \\
\text { installatio } \\
\text { n angle } \\
\text { (A) } /{ }^{\circ}\end{array}$ & $\begin{array}{l}\text { radial } \\
\text { installatio } \\
\mathrm{n} \text { angle } \\
\text { (B) } 1{ }^{\circ}\end{array}$ & $\begin{array}{l}\text { phase } \\
\text { angle } \\
\text { of the } \\
\text { mixing } \\
\text { arm } \\
\text { (C) } \\
\text { p }^{\circ}\end{array}$ & $\begin{array}{l}\text { inclinatio } \\
\mathrm{n} \text { angle } \\
\text { of the } \\
\text { drum } \\
\text { (D) } /^{\circ}\end{array}$ & $\begin{array}{l}\text { rotation } \\
\text { speed of } \\
\text { the drum } \\
\text { (E) } \\
\text { /rpm }\end{array}$ & $\begin{array}{l}\text { aggreg } \\
\text { ate } 1 \\
\left(\mathrm{C}_{\mathrm{v} 1}\right. \\
)\end{array}$ & $\begin{array}{l}\text { aggreg } \\
\text { ate } 2 \\
\left(\mathrm{C}_{\mathrm{v} 2}\right. \\
)\end{array}$ & $\begin{array}{c}\text { aggreg } \\
\text { ate } 3 \\
\left(\mathrm{C}_{\mathrm{v} 3}\right. \\
)\end{array}$ \\
\hline 1 & 46 & 36 & 40 & 4 & 10 & 0.428 & 0.188 & 0.610 \\
\hline 2 & 40 & 36 & 40 & 4 & 8 & 0.451 & 0.232 & 0.708 \\
\hline 3 & 40 & 40 & 40 & 2 & 8 & 0.455 & 0.234 & 0.688 \\
\hline 4 & 46 & 36 & 60 & 4 & 8 & 0.533 & 0.386 & 1.361 \\
\hline 5 & 40 & 36 & 60 & 4 & 10 & 0.474 & 0.290 & 0.819 \\
\hline 6 & 46 & 36 & 40 & 4 & 6 & 0.573 & 0.226 & 0.843 \\
\hline 7 & 40 & 36 & 60 & 2 & 8 & 0.424 & 0.272 & 0.899 \\
\hline 8 & 34 & 36 & 40 & 6 & 8 & 0.397 & 0.188 & 0.609 \\
\hline 9 & 40 & 40 & 60 & 4 & 8 & 0.528 & 0.445 & 1.248 \\
\hline
\end{tabular}




\begin{tabular}{|c|c|c|c|c|c|c|c|c|}
\hline 10 & 40 & 36 & 40 & 4 & 8 & 0.451 & 0.232 & 0.708 \\
\hline 11 & 40 & 36 & 60 & 4 & 6 & 0.576 & 0.401 & 1.726 \\
\hline 12 & 40 & 40 & 40 & 4 & 10 & 0.358 & 0.157 & 0.657 \\
\hline 13 & 40 & 36 & 40 & 4 & 8 & 0.451 & 0.232 & 0.708 \\
\hline 14 & 46 & 36 & 40 & 2 & 8 & 0.489 & 0.222 & 0.754 \\
\hline 15 & 40 & 32 & 40 & 2 & 8 & 0.448 & 0.196 & 0.663 \\
\hline 16 & 34 & 32 & 40 & 4 & 8 & 0.396 & 0.188 & 0.612 \\
\hline 17 & 40 & 36 & 40 & 4 & 8 & 0.451 & 0.232 & 0.708 \\
\hline 18 & 34 & 36 & 40 & 2 & 8 & 0.399 & 0.192 & 0.670 \\
\hline 19 & 40 & 32 & 20 & 4 & 8 & 0.578 & 0.367 & 0.815 \\
\hline 20 & 40 & 36 & 40 & 4 & 8 & 0.451 & 0.232 & 0.708 \\
\hline 21 & 40 & 36 & 40 & 4 & 8 & 0.451 & 0.232 & 0.708 \\
\hline 22 & 40 & 36 & 40 & 2 & 10 & 0.418 & 0.178 & 0.591 \\
\hline 23 & 46 & 32 & 40 & 4 & 8 & 0.509 & 0.240 & 0.765 \\
\hline 24 & 40 & 36 & 20 & 4 & 10 & 0.476 & 0.287 & 0.716 \\
\hline 25 & 40 & 36 & 20 & 6 & 8 & 0.447 & 0.255 & 0.622 \\
\hline 26 & 40 & 36 & 40 & 6 & 6 & 0.496 & 0.239 & 0.841 \\
\hline 27 & 40 & 32 & 40 & 4 & 10 & 0.421 & 0.182 & 0.642 \\
\hline 28 & 40 & 36 & 40 & 6 & 10 & 0.366 & 0.185 & 0.567 \\
\hline 29 & 46 & 36 & 20 & 4 & 8 & 0.539 & 0.299 & 0.718 \\
\hline 30 & 34 & 36 & 40 & 4 & 10 & 0.365 & 0.160 & 0.522 \\
\hline 31 & 34 & 36 & 60 & 4 & 8 & 0.430 & 0.325 & 1.034 \\
\hline 32 & 40 & 40 & 40 & 4 & 6 & 0.495 & 0.237 & 0.877 \\
\hline 33 & 40 & 32 & 40 & 6 & 8 & 0.456 & 0.243 & 0.681 \\
\hline 34 & 46 & 40 & 40 & 4 & 8 & 0.516 & 0.256 & 0.892 \\
\hline 35 & 40 & 40 & 20 & 4 & 8 & 0.563 & 0.346 & 0.719 \\
\hline 36 & 34 & 40 & 40 & 4 & 8 & 0.387 & 0.187 & 0.624 \\
\hline 37 & 34 & 36 & 40 & 4 & 6 & 0.461 & 0.230 & 0.826 \\
\hline 38 & 34 & 36 & 20 & 4 & 8 & 0.543 & 0.365 & 0.652 \\
\hline 39 & 40 & 40 & 40 & 6 & 8 & 0.466 & 0.249 & 0.789 \\
\hline 40 & 40 & 36 & 20 & 2 & 8 & 0.609 & 0.378 & 0.753 \\
\hline
\end{tabular}




\begin{tabular}{lllllllll}
\hline 41 & 40 & 36 & 20 & 4 & 6 & 0.664 & 0.403 & 0.911 \\
42 & 40 & 36 & 40 & 2 & 6 & 0.521 & 0.220 & 0.797 \\
43 & 40 & 36 & 60 & 6 & 8 & 0.524 & 0.460 & 1.530 \\
44 & 40 & 32 & 60 & 4 & 8 & 0.449 & 0.318 & 0.944 \\
45 & 40 & 32 & 40 & 4 & 6 & 0.506 & 0.212 & 0.831 \\
46 & 46 & 36 & 40 & 6 & 8 & 0.542 & 0.275 & 0.894
\end{tabular}

433 The simulation results are analyzed by response surface method, the mathematical model between the discrete 434 coefficient and each factor of aggregate 1 is shown in eq.(7). The mathematical model between the discrete 435 coefficient and each factor of aggregate 2 is shown in eq.(8). The mathematical model between the discrete 436 coefficient and each factor of aggregate 3 is shown in eq. (9). Table 5, table 6 and table 7 are the variance analysis 437 tables of each model.

$$
\begin{aligned}
C v 1= & 0.21769+0.00583 A-0.00579 B-0.00738 C-0.07563 D+0.10353 E+ \\
& 0.00017 A B+0.00001 A C+0.00114 A D-0.00102 A E+0.00297 B C+ \\
& 0.00009 B D-0.00163 B E+0.00102 C D-0.00071 C E-0.00161 D E
\end{aligned}
$$

$$
C v 2=1.16815+0.00052 A-0.00475 B-0.06012 C-0.0647 D+0.10344 E+
$$$$
0.00018 A B+0.00026 A C+0.0012 A D+0.00066 A E+0.00046 B C-
$$$$
0.001 B D-0.00156 B E+0.00195 C D+0.00004 C E-0.00075 D E
$$

$$
\begin{aligned}
C v 3= & 6.2745-0.07282 A-0.10148 B-0.08952 C-0.38336 D-0.02615 E+ \\
& 0.00120 A B+0.00054 A C+0.00417 A D+0.00148 A E+0.00125 B C+ \\
& 0.00264 B D-0.00094 B E+0.00477 C D-0.00445 C E-0.00422 D E
\end{aligned}
$$

\begin{tabular}{|c|c|c|c|c|c|c|}
\hline $\begin{array}{l}\text { Source of } \\
\text { variance }\end{array}$ & $\begin{array}{l}\text { Sum of } \\
\text { squares }\end{array}$ & $\begin{array}{l}\text { degree of } \\
\text { freedom }\end{array}$ & $\begin{array}{l}\text { Root } \\
\text { mean } \\
\text { square }\end{array}$ & F value & $\mathrm{P}$ value & Saliency \\
\hline Model & 0.19 & 20 & $\begin{array}{c}0.00944 \\
1\end{array}$ & 16.06 & $<0.0001$ & $\begin{array}{l}\text { significan } \\
\text { t. }\end{array}$ \\
\hline A & 0.035 & 1 & 0.035 & 59.41 & $<0.0001$ & \\
\hline B & $5.013 \mathrm{E}-07$ & 1 & $\begin{array}{c}5.013 \mathrm{E}- \\
07\end{array}$ & 0.0008526 & 0.9769 & \\
\hline
\end{tabular}

TABLE 5. Aggregate 1 variance analysis. 


\begin{tabular}{|c|c|c|c|c|c|}
\hline $\mathrm{C}$ & 0.014 & 1 & 0.014 & 24.58 & $<0.0001$ \\
\hline $\mathrm{D}$ & 0.000307 & 1 & $\begin{array}{c}0.00030 \\
7\end{array}$ & 0.52 & 0.4767 \\
\hline $\mathrm{E}$ & 0.061 & 1 & 0.061 & 103.35 & $<0.0001$ \\
\hline $\mathrm{AB}$ & 0.00006468 & 1 & $\begin{array}{c}0.00006 \\
468\end{array}$ & 0.11 & 0.7429 \\
\hline $\mathrm{AC}$ & 0.002842 & 1 & $\begin{array}{c}0.00284 \\
2\end{array}$ & 4.83 & 0.0374 \\
\hline $\mathrm{AD}$ & 0.0007506 & 1 & $\begin{array}{c}0.00075 \\
06\end{array}$ & 1.28 & 0.2693 \\
\hline $\mathrm{AE}$ & 0.0005979 & 1 & $\begin{array}{c}0.00059 \\
79\end{array}$ & 1.02 & 0.3229 \\
\hline $\mathrm{BC}$ & 0.002252 & 1 & $\begin{array}{c}0.00225 \\
2\end{array}$ & 3.83 & 0.0616 \\
\hline $\mathrm{BD}$ & 0.000001941 & 1 & $\begin{array}{c}0.00000 \\
1941\end{array}$ & 0.003301 & 0.9546 \\
\hline $\mathrm{BE}$ & 0.000684 & 1 & $\begin{array}{c}0.00068 \\
4\end{array}$ & 1.16 & 0.2911 \\
\hline $\mathrm{CD}$ & 0.017 & 1 & 0.017 & 29.29 & $<0.0001$ \\
\hline $\mathrm{CE}$ & 0.00188 & 1 & 0.00188 & 3.2 & 0.0859 \\
\hline $\mathrm{DE}$ & 0.0001651 & 1 & $\begin{array}{c}0.00016 \\
51\end{array}$ & 0.28 & 0.6008 \\
\hline
\end{tabular}

TABLE 6. Model analysis of variance table for aggregate 2.

\begin{tabular}{ccccccc}
\hline Source of & quadratic & $\begin{array}{c}\text { degree } \\
\text { of }\end{array}$ & $\begin{array}{c}\text { root- } \\
\text { mean- }\end{array}$ & F value & P value & $\begin{array}{c}\text { Significa } \\
\text { nce }\end{array}$ \\
& sum & freedom & square & & & \\
\hline Model & 0.26 & 20 & 0.013 & 28.92 & $<0.0001$ & significan \\
& & & & & & t. \\
A & 0.004086 & 1 & 0.004086 & 9.19 & 0.0056 & \\
B & 0.00168 & 1 & 0.00168 & 3.78 & 0.0633 & \\
C & 0.002431 & 1 & 0.002431 & 5.47 & 0.0277 & \\
D & 0.002544 & 1 & 0.002544 & 5.72 & 0.0246 & \\
\hline
\end{tabular}




\begin{tabular}{|c|c|c|c|c|c|}
\hline $\mathrm{E}$ & 0.018 & 1 & 0.018 & 41.01 & $<0.0001$ \\
\hline $\mathrm{AB}$ & 0.00007152 & 1 & $\begin{array}{c}0.000071 \\
52\end{array}$ & 0.16 & 0.6918 \\
\hline $\mathrm{AC}$ & 0.003979 & 1 & 0.003979 & 8.95 & 0.0062 \\
\hline $\mathrm{AD}$ & 0.000824 & 1 & 0.000824 & 1.85 & 0.1856 \\
\hline $\mathrm{AE}$ & 0.0002495 & 1 & $\begin{array}{c}0.000249 \\
5\end{array}$ & 0.56 & 0.4609 \\
\hline $\mathrm{BC}$ & 0.005391 & 1 & 0.005391 & 12.12 & 0.0018 \\
\hline $\mathrm{BD}$ & 0.0002611 & 1 & $\begin{array}{c}0.000261 \\
1\end{array}$ & 0.59 & 0.4508 \\
\hline $\mathrm{BE}$ & 0.0006193 & 1 & $\begin{array}{c}0.000619 \\
3\end{array}$ & 1.39 & 0.2491 \\
\hline $\mathrm{CD}$ & 0.024 & 1 & 0.024 & 54.77 & $<0.0001$ \\
\hline $\mathrm{CE}$ & 0.000008702 & 1 & $\begin{array}{c}0.000008 \\
702\end{array}$ & 0.02 & 0.8899 \\
\hline $\mathrm{DE}$ & 0.00003555 & 1 & $\begin{array}{c}0.000035 \\
55\end{array}$ & 0.08 & 0.7797 \\
\hline
\end{tabular}

TABLE 7. Model analysis of variance table for aggregate 3.

\begin{tabular}{|c|c|c|c|c|c|c|}
\hline & & & root & & & \\
\hline $\begin{array}{l}\text { Source of } \\
\text { Variance }\end{array}$ & $\begin{array}{c}\text { quadratic } \\
\text { sum }\end{array}$ & $\begin{array}{l}\text { degree of } \\
\text { freedom }\end{array}$ & mean & F Value & P Value & $\begin{array}{c}\text { Significa } \\
\text { nce }\end{array}$ \\
\hline Model & 2.4 & 20 & 0.12 & 16.19 & $<0.0001$ & $\begin{array}{l}\text { significan } \\
\text { t. }\end{array}$ \\
\hline A & 0.1 & 1 & 0.1 & 14.01 & 0.001 & \\
\hline B & 0.018 & 1 & 0.018 & 2.47 & 0.1287 & \\
\hline $\mathrm{C}$ & 0.83 & 1 & 0.83 & 112.64 & $<0.0001$ & \\
\hline D & 0.032 & 1 & 0.032 & 4.34 & 0.0475 & \\
\hline E & 0.4 & 1 & 0.4 & 53.92 & $<0.0001$ & \\
\hline $\mathrm{AB}$ & 0.003326 & 1 & $\begin{array}{c}0.00332 \\
6\end{array}$ & 0.45 & 0.509 & \\
\hline $\mathrm{AC}$ & 0.017 & 1 & 0.017 & 2.29 & 0.1429 & \\
\hline $\mathrm{AD}$ & 0.01 & 1 & 0.01 & 1.35 & 0.2563 & \\
\hline
\end{tabular}




\begin{tabular}{|c|c|c|c|c|c|}
\hline & & & 0.00125 & & \\
\hline $\mathrm{AE}$ & 0.001254 & 1 & 4 & 0.17 & 0.6843 \\
\hline $\mathrm{BC}$ & 0.04 & 1 & 0.04 & 5.41 & 0.0284 \\
\hline $\mathrm{BD}$ & 0.001782 & 1 & $\begin{array}{c}0.00178 \\
2\end{array}$ & 0.24 & 0.6282 \\
\hline $\mathrm{BE}$ & 0.0002274 & 1 & $\begin{array}{c}0.00022 \\
74\end{array}$ & 0.031 & 0.8624 \\
\hline $\mathrm{CD}$ & 0.15 & 1 & 0.15 & 19.65 & 0.0002 \\
\hline $\mathrm{CE}$ & 0.13 & 1 & 0.13 & 17.13 & 0.0003 \\
\hline $\mathrm{DE}$ & 0.001141 & 1 & $\begin{array}{c}0.00114 \\
1\end{array}$ & 0.15 & 0.6981 \\
\hline
\end{tabular}

444 According to table 5, table 6 , and table 7 , the $\mathrm{P}$ value of the fitting model is less than 0.0001 , indicating that the 445 fitting effect is very significant. In response surface analysis, when $\mathrm{P}$ value is less than 0.05 , it indicates that the 446 influence degree of this factor is more significant.The significance order of the influence of single factor on the 447 dispersion coefficient of aggregate 1 is as follows: $E>A>C>D>B$, Among them, factor A, factor $\mathrm{C}$, and factor $\mathrm{E}$ 448 have significant influence. The significant order of the influence of each interaction factor on the dispersion coefficient 449 of aggregate 1 is as follows:

$450 C D>A C>B C>C E>A D>B E>A E>D E>A B>B D$. Among them, factors $\mathrm{AC}$,and factors $\mathrm{CD}$ have 451 significant influence.The significance order of the influence of single factor on the dispersion coefficient of aggregate 2 452 is as follows: $E>A>D>C>B$. Among them, factor A, factor C, factor D and factor $\mathrm{E}$ have significant 453 influence.The significant order of the influence of each interaction factor on the dispersion coefficient of aggregate 2 is 454 as follows:

$455 C D>B C>A C>A D>B E>B D>A E>A B>D E>C E$. Among them, factors AC, factors BC and factors CD have 456 significant influence.The significance order of the influence of single factor on the dispersion coefficient of aggregate 3 457 is as follows: $C>E>A>D>B$, Among them, factor A, factor $\mathrm{C}$, factor $\mathrm{D}$ and factor $\mathrm{E}$ have significant 458 influence.The significant order of the influence of each interaction factor on the dispersion coefficient of aggregate 3 is 459 as follows:

$460 C D>C E>B C>A C>A D>A B>B D>A E>D E>B E$.Among them, factors BC, factors $\mathrm{CD}$, and factors CE 461 have significant influence. 
463 In order to test the rationality of the fitting model, the randomness and normality of the residual are analyzed. The 464 relationship between residual and predicted value of aggregate fitting model is shown in Fig.24. The student residual is 465 randomly distributed on both sides of the predicted value, it shows that there is no correlation between residual and 466 predicted value, that is, residual is caused by random error. The residual normal probability distribution of aggregate 467 fitting model is shown in Fig.25. The residuals of students are basically distributed on the straight line of normal 468 distribution, that is, the residuals are subject to normal distribution. Therefore, the fitting model is reasonable, and the 469 effect of various factors can be predicted by response surface method.

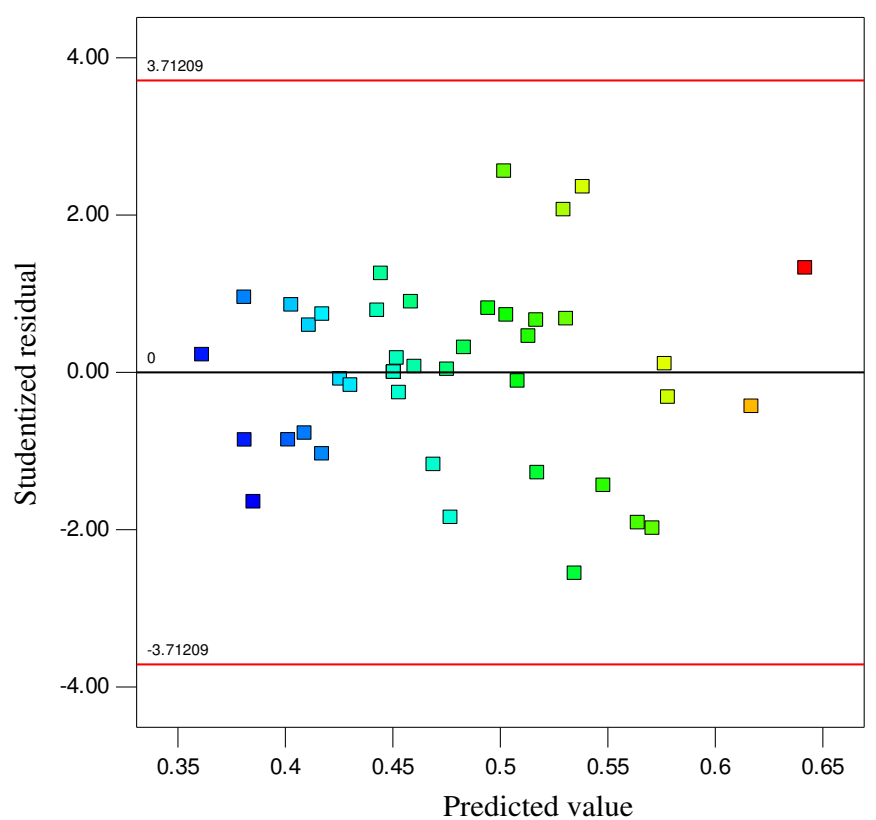

(a) 


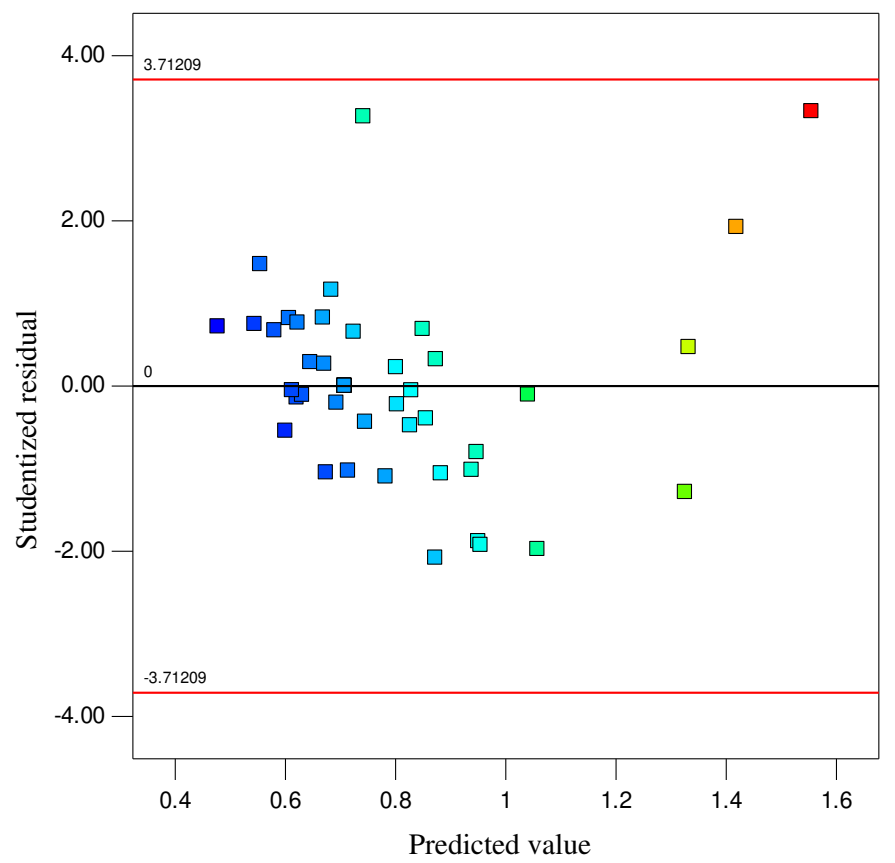

(b)

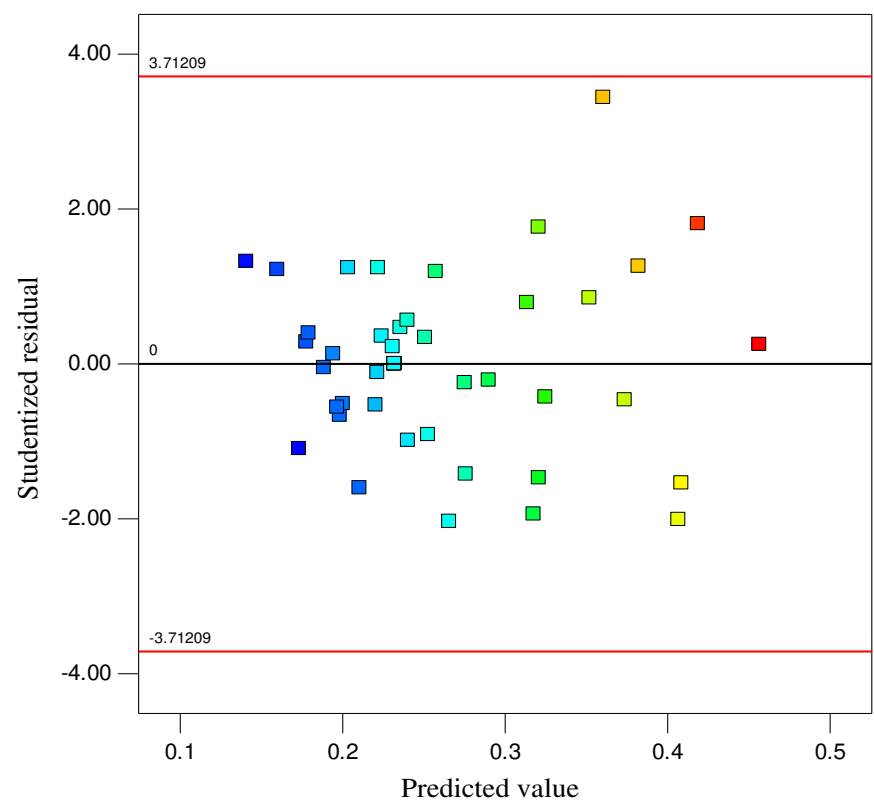

(c)

FIGURE 24. Relationship between student residual and predicted value. 


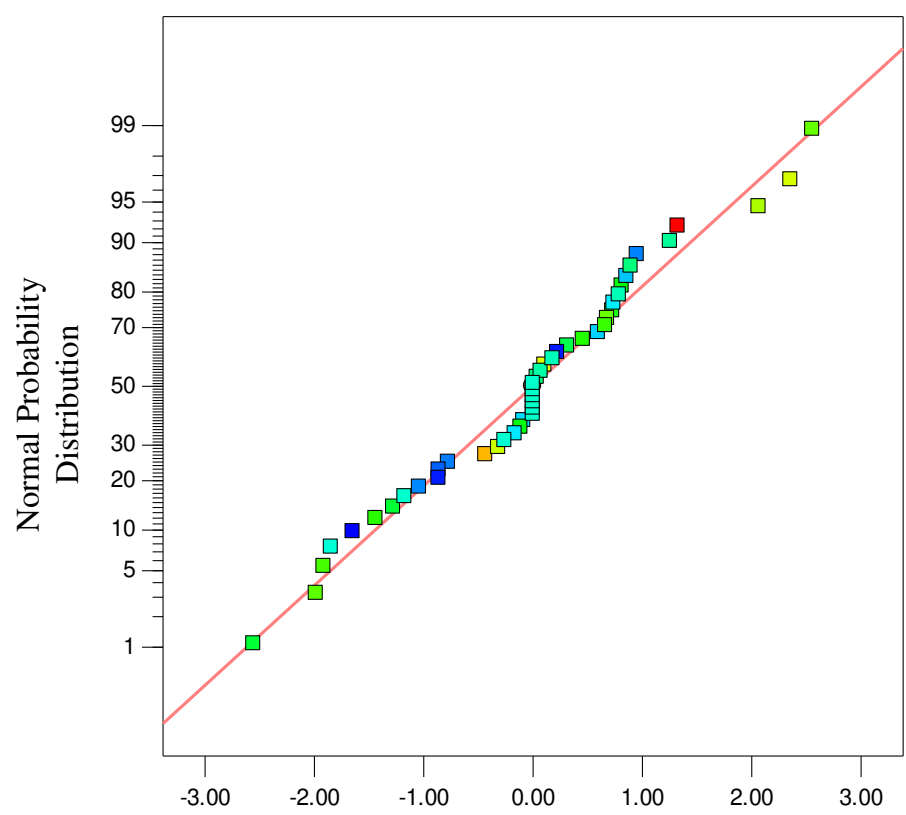

Studentized residual

(a)

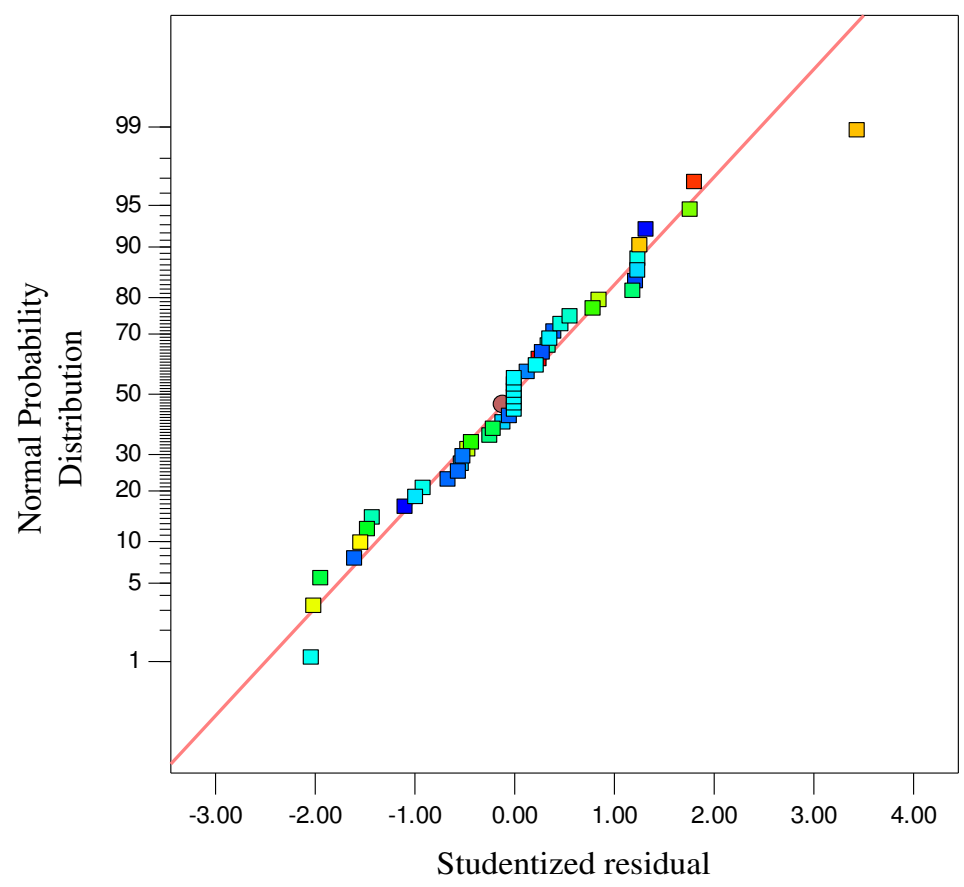

(b) 


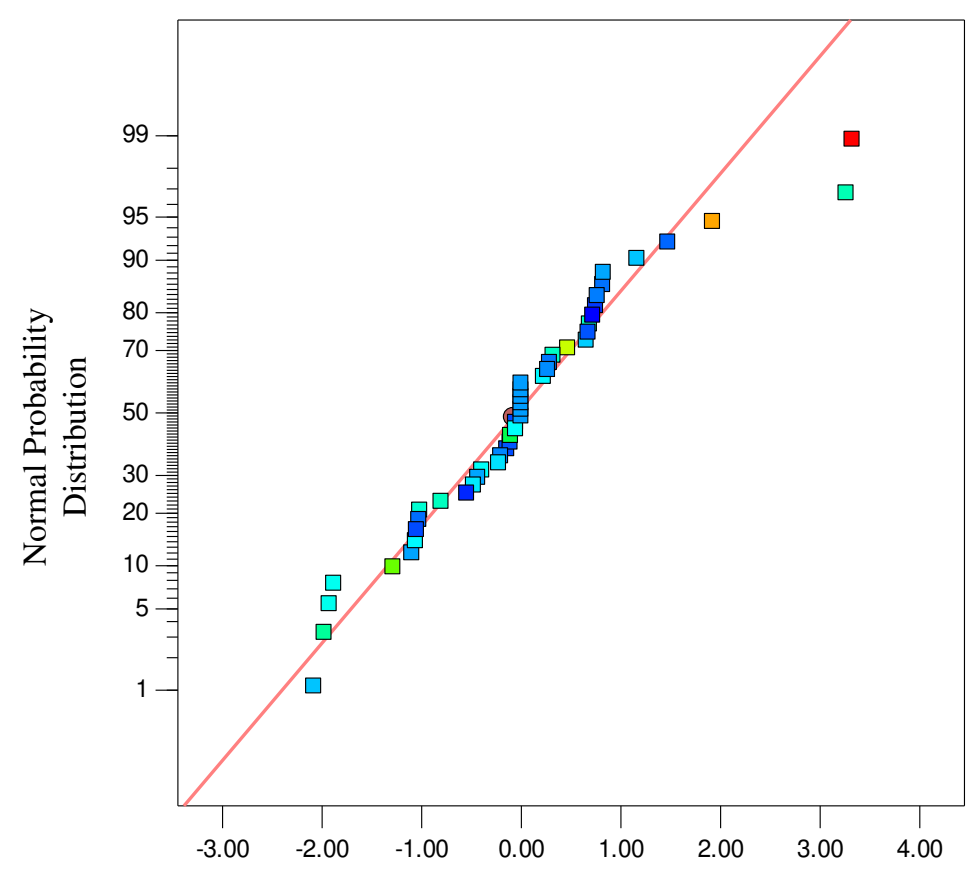

Studentized residual

(c)

FIGURE 25. Normal probability distribution of student residuals.

$484 \quad 4.4$ Interaction factor analysis

485 Among the interaction factors, the interactions of drum angle and phase angle of mixing arm, blade axial installation 486 angle and phase angle of mixing arm have significant effect on the dispersion coefficient of aggregate 1.The response 487 surface relationship between dispersion coefficient and significant interaction factor of aggregate 1 is shown in Fig. 26. 


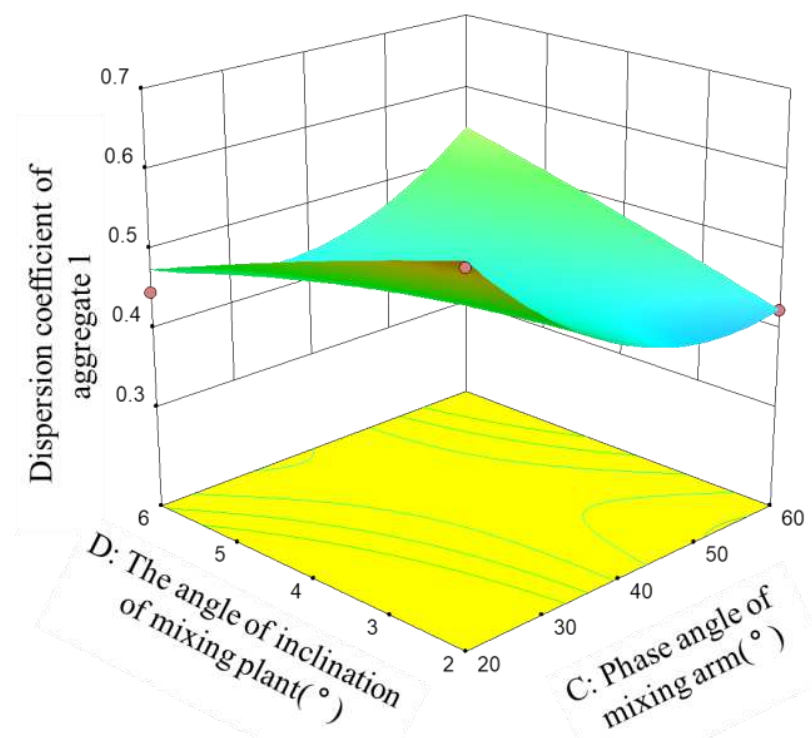

(a)

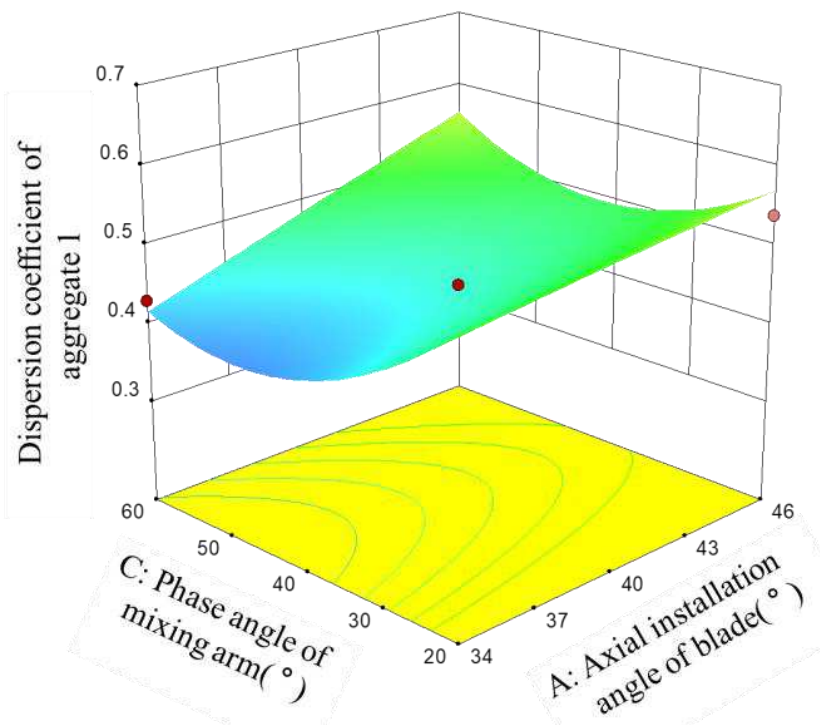

FIGURE 26. The response surface relationship between dispersion coefficient and significant interaction factor of aggregate 1.

As shown in Figure 26 (a), when the phase angle of the mixing arm is $20^{\circ}$, the dispersion coefficient of aggregate 1 decreases with the increase of the inclination of the drum; When the phase angle of the mixing arm is $60^{\circ}$, the 496 dispersion coefficient of aggregate 1 increases with the increase of the inclination of the drum. As shown in Figure 27 (b), if the phase angle of the mixing arm is any value, the dispersion coefficient of aggregate 1 will decrease with the decrease of the axial installation angle.Among them, when the phase angle of the mixing arm is $60^{\circ}$, its dispersion 
coefficient decreases faster.

500 Among the interaction factors, the interactions of Phase angle of mixing arm and axial installation angle of blade, 501 blade radial installation angle and mixing arm phase angle, drum inclination angle and phase angle of mixing arm have 502 significant effect on the dispersion coefficient of aggregate 2. The response surface relationship between dispersion 503 coefficient and significant interaction factor of aggregate 2 is shown in Fig. 27.

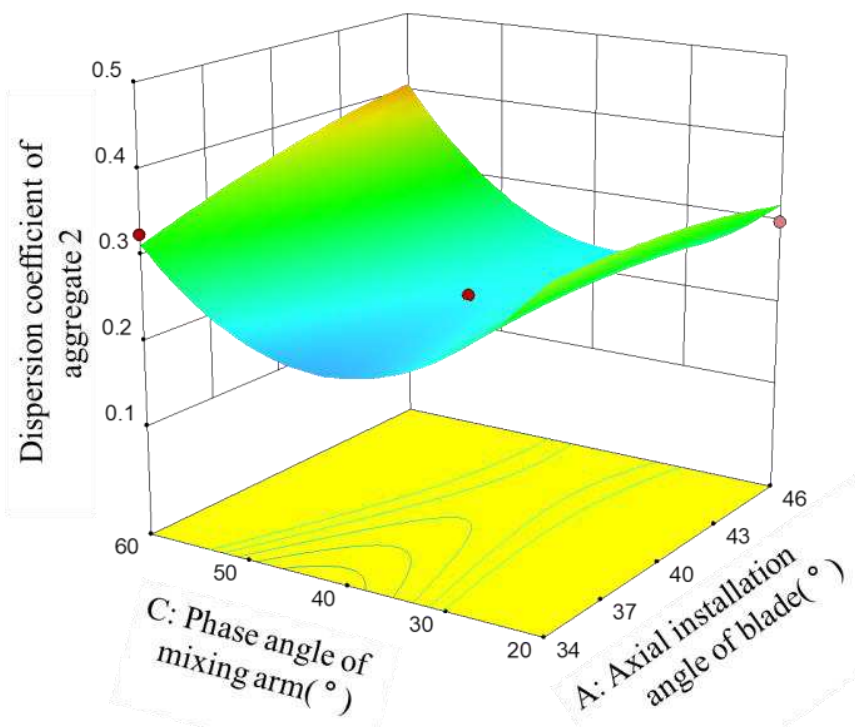

a)

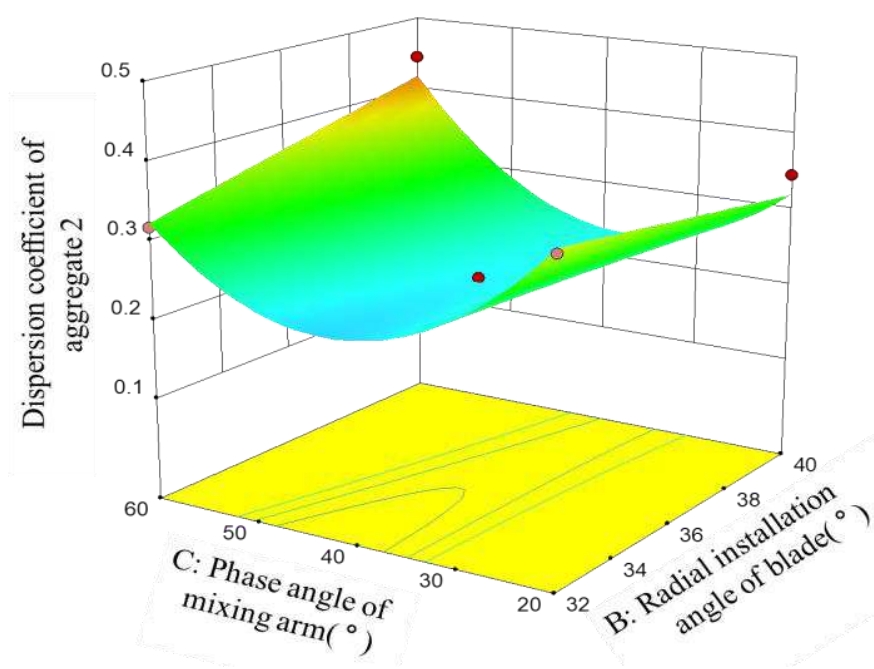




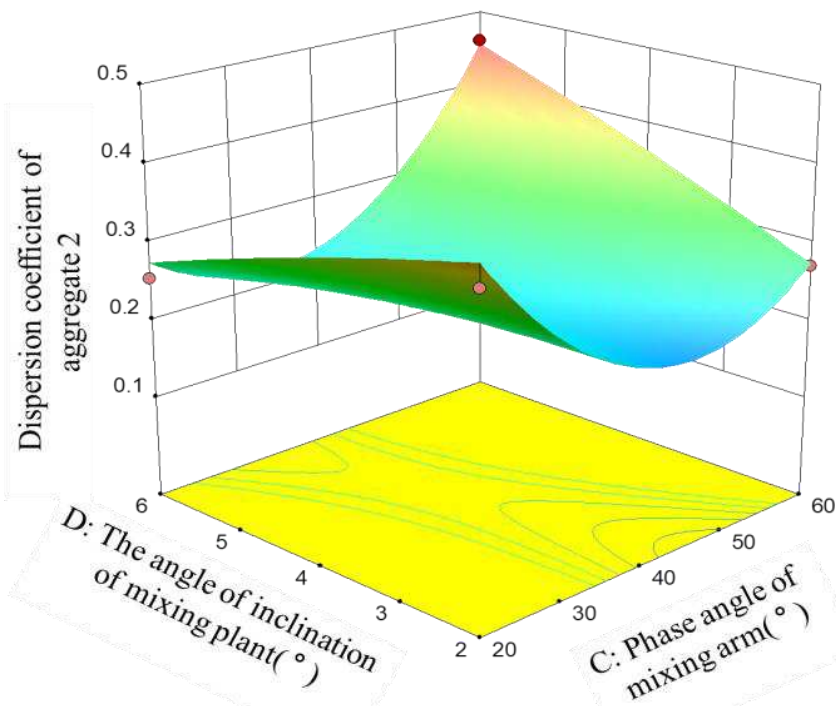

c)

FIGURE 27. The response surface relationship between dispersion coefficient and significant interaction factor of aggregate 2 .

511 As shown in Figure 28, the interaction between the phase angle of mixing arm and the installation angle of blade

512 (axial and radial) has a similar effect on the uniformity of aggregate 2 . When the phase angle of the mixing arm is 513 constant, the change of the axial and radial installation angle of the blade has little influence on the dispersion 514 coefficient of aggregate 2 , among them, when the phase angle of the mixing arm is $60^{\circ}$, the effect is relatively 515 obvious. When the phase angle of the mixing arm changes, the inclination of the drum has a great influence on the 516 uniformity of aggregate 2 . When the phase angle is $20^{\circ}$, the dispersion coefficient of aggregate 2 decreases with the 517 increase of the inclination of the drum. When the phase angle is $60^{\circ}$, the dispersion coefficient of aggregate 2 increases 518 with the increase of the inclination of the drum.

519 Among the interaction factors, the interactions of blade radial installation angle and phase angle of mixing arm, drum 520 inclination angle and Phase angle of mixing arm , drum rotation speed and phase angle of mixing arm have 521 significant effect on the dispersion coefficient of aggregate 3. The response surface relationship between dispersion coefficient and significant interaction factor of aggregate 3 is shown in Fig. 28. 


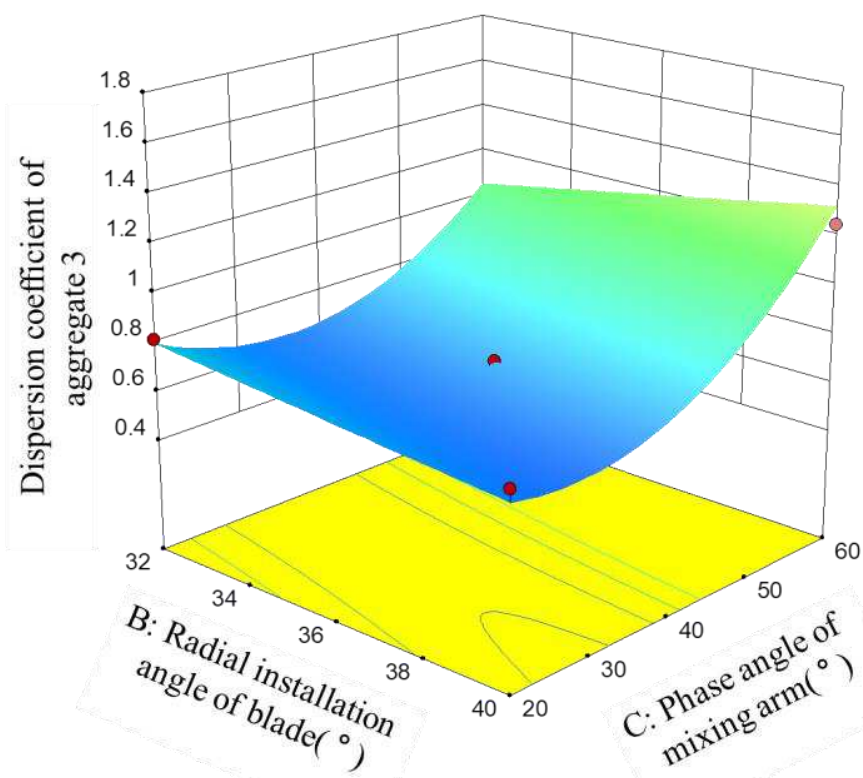

a)

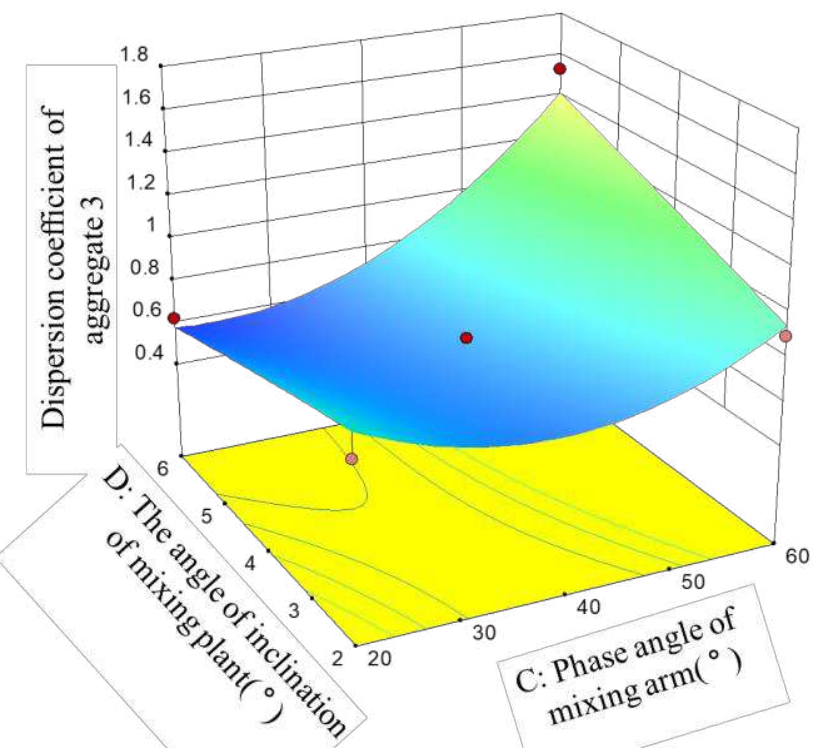




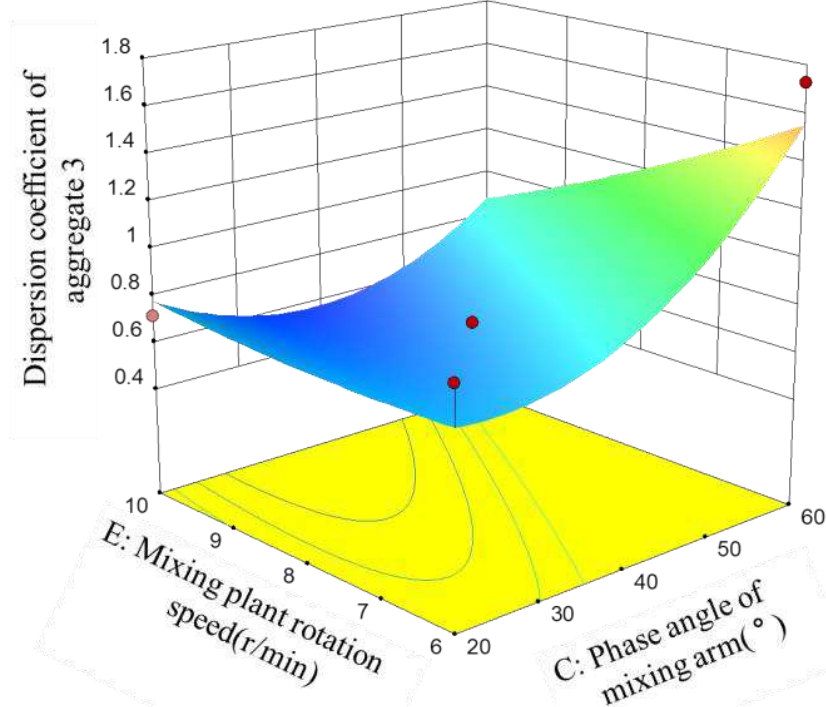

FIGURE 28. The response surface relationship between dispersion coefficient and significant interaction factor of aggregate 3 .

As shown in Fig.28, When the phase angle of the mixing arm is $20^{\circ}$, blade radial installation angle, drum inclination angle,and drum rotation speed have little influence on the dispersion coefficient of aggregate 3; When the phase angle of mixing arm is $60^{\circ}$, the dispersion coefficient of aggregate 3 increases with the increase of blade radial installation angle, decreases with the decrease of drum inclination angle, and increases with the decrease of drum rotation speed.Therefore, When the phase angle of the mixing arm is large, drum rotation speed, drum inclination angle and blade radial installation angle have obvious influence on the uniformity of aggregate 3 . Therefore, when the phase angle of the mixing arm is large, the speed of the drum, the inclination of the drum and the radial installation angle of the blades have obvious influence on the uniformity of aggregate 3. As shown in Fig.28 (c), when the drum speed is 10r/min, the dispersion coefficient of aggregate 3 decreases first and then increases with the increase of the phase angle of the mixing arm, and the change range is small. When the rotating speed of the drum is $6 \mathrm{r} / \mathrm{min}$, the dispersion coefficient of aggregate 3 increases greatly with the increases of the phase angle of the mixing arm. The results show 541 that when the phase angle of the mixing arm is large and the rotating speed of the drum is reduced, the segregation of aggregate 3 is easy to increase.

As shown in Fig.26 (a), Fig.27 (c), and Fig.28 (b), the interaction between the angle of drum and the phase angle of mixing arm has a significant effect on the dispersion coefficient of the three kinds of aggregate. In order to improve the mixing uniformity, the phase angle when the inclination of the drum is large should be smaller than that when the 
546 inclination of the drum is small. When the inclination of the drum is constant, the phase angle corresponding to the low

547 point of the response surface of the discrete coefficient of aggregate decreases in turn, that is, a smaller phase angle

548 should be arranged for the mixing of large particles.

5494.5 Response surface optimization results

550 Taking the minimum value of discrete coefficient as the optimization objective, the values of each parameter are 551 obtained as follows:

552 The blade axial installation angle is $34.896^{\circ}$, the blade radial installation angle is $38.389^{\circ}$, the phase angle of the mixing $553 \operatorname{arm}$ is $31.676^{\circ}$, the drum inclination angle is $5.999^{\circ}$, and the drum rotational speed is $9.997 \mathrm{r} / \mathrm{min}$. After rounding, the 554 blade axial installation angle is $35^{\circ}$, the blade radial installation angle is $38^{\circ}$, the phase angle of the mixing arm is $32^{\circ}$, 555 the drum inclination angle is $6^{\circ}$, and the drum rotational speed is $10 \mathrm{r} / \mathrm{min}$.

\section{Conclusions}

557 (1) Increasing the rotation speed and reducing the axial installation angle of the blade can reduce the dispersion 558 coefficient of the aggregate. When the feed rate is unchanged, only increasing the phase angle will cause the filling rate 559 of the stirring chamber to increase and the stirring uniformity to decrease. Therefore, in order to obtain better stirring 560 uniformity, the phase angle when the drum inclination angle is larger should be smaller than the phase angle when the 561 drum inclination angle is small, and it is not appropriate to use a larger phase angle for the stirring of large-size 562 particles.

563 (2) Through the response surface method, the significant relationship between the influence of each single factor and its 564 interaction on the discrete coefficients of the three aggregates is obtained.

565 The significant factors affecting the dispersion coefficient of aggregate 1 and the significant relationship are: $n>\beta>\varphi$, In the interaction term, $\varphi$ and $\gamma, \varphi$ and $\beta$ have significant influence. The significant factors and the

567 significant relationship of the dispersion coefficient of aggregate 2 are: $n>\beta>\gamma>\varphi$, and among the interaction 568 terms, $\varphi$ and $\gamma, \varphi$ and $\alpha, \varphi$ and $\beta$ have significant influences; The significant factors and the significant 569 relationship of the dispersion coefficient of aggregate 3 are: $\varphi>n>\beta>\gamma$, and among the interaction terms, $570 \varphi$ and $\gamma, \varphi$ and $n$, and $\varphi$ and $\alpha$ have significant effects.

571 Taking the lowest dispersion coefficient as the goal, the best parameter matching is: $\alpha=38^{\circ}, \beta=35^{\circ}, \gamma=6^{\circ}$, 
$\mathrm{n}=10 \mathrm{r} / \mathrm{min}, \varphi=32^{\circ}$

\section{Declarations:}

\section{Data Availability Statement}

All data, models, and code generated or used during the study appear in the submitted article.

\section{Competing interests}

We declare that we have no financial and personal relationships with other people or organizations that can inappropriately influence our work, there is no professional or other personal interest of any nature or kind in any product, service and/or company that could be construed as influencing the position presented in, or the review of,

580 the manuscript entitled "Simulation analysis of the significance and interaction of influencing factors on mixing 581 uniformity of double drum recycling mixing plant".

\section{Funding}

The Natural Science Basic Research Plan in Shaanxi Province [number 2017JM5077] provided financial support for thesis research design and data collection, simulation analysis, and manuscript writing.

\section{Authors' contributions}

The overarching research goals were developed by MA Deng-cheng, CHEN Chao and LIU Chenqi. MA Deng-cheng provided the concept and wrote the first draft of the manuscript. CHEN Chao established the models and LIU Chenqi performed simulation analysis. MA Deng-cheng analyzed the calculated results. All authors replied to reviewers' comments and revised the final version.

\section{Acknowledgements}

This work was supported by the Natural Science Basic Research Plan in Shaanxi Province [number 2017JM5077] .

References :

595 [1] Ma Dengcheng, Liukang. Modeling and Simulation of Mixing Uniformity of Double Drum Regenerative Mixing

596 Equipment [J]. Journal of Huazhong University of Science and Technology(Natural Science edition), 2020, $29(3): 17-22$.

597 [2] Liu Bo, Li Ziguang, Da Yunfeng. Study on the Inclination Angle of Outer Cylinder Mixing

598 Blade of Double Drum Continuous Mixing Equipment[J]. Highways \& Automotive Applications,2014(4):150-152.

599 [3] Zhao Lijun, Shen Yan, Deng Xin, et al. Parameters Matching of Mixing Blades for Asphalt Mixture Mixer Based on EDEM [J]. Journal of Zhengzhou University (Engineering Science edition),2019,40(3): 79-84. 
601 [4] SIMONS T A H, BENSMANN S, ZIGAN S, et al. Characterization of granular mixing in a helical ribbon blade 602 blender[J]. Powder Technology, 2016, 293(5):1-11.

603 [5] SAKAI M, SHIGETO Y, BASINSKAS G, et al. Discrete element simulation for the evaluation of solid mixing in an 604 industrial blender[J]. Chemical Engineering Journal, 2015, 279(11):821-839.

605 [6] John Milstead. Asphalt drum mixer with curved scoop-like mixing tips[P]. US Patent:5380082,1995-10-1.

606 [7] Larry W.Hudman, J.Greg Renegar, Michael C.Varner. Method and apparatus for adapting asphalt dryer/mixer to 607 minimize asphalt build-up[P]. United States Patent:8172448, 2009-09-03.

608 [8] I. Choustere. Cold Milling and Manufacturing Recycled Asphaltic Concrete Mixtures by Drum Mixing Process in 609 Florida. Techical Bulletin, BGO - Tech. Paper100.

610 [9] Ivica Androjic, Zlata Dolac ek Alduk. Analysis of energy consumption in the production of hot mix asphalt (batch 611 mix plant) [J]. Can. J. Civ. Eng. Vol. 43, 2016

612 [10] D. Peinado, M. de Vega, N. García-Hernando, C. Marugán-Cruz. Energy and exergy analysis in an asphalt plant’s 613 rotary dryer[J].Applied Thermal Engineering 31 (2011) 1039-1049.

614 [11] Jon Elvar Wallevik, Olafur Haralds Wallevik. Analysis of shear rate inside a concrete truck mixer[J].Cement and 615 Concrete Research,95 (2017) 9-17

616 [12] Justas BRAŽIŪNAS.Investigation into technological parameters of bitumen batching in an asphalt mixing 617 plant[J].Journal of Civil Engineering and Management,2015 , 21(7): 958-965

618 [13] HenrikasSivilevičius,KęstutisVislavičius.Simulation of composition of recycled hot-mix asphalt mixture produced in 619 asphalt mixing plant[J].Construction and Building Materials,2019,214:17-27

620 [14] M.Mohajeri, A. A .A.Molenaar. Blending of virgin bitumen and RA binder in mixtures with high amounts of RA[J]. 621 Advances in Asphalt Materials, 2015:363-392.

622 [15] Yu Shuqin, Guo Shiyong, Sun Yibing. The Study About Improving the Accuracy of Measurement of the Double-Roller 623 Bituminous Mixing Machine ASTEC[J]. Journal of Qingdao University of Technology,2008(05):115-119.

624 [16] Cao Yongtao. Design Proposal for Continuous Asphalt Mixing Plant with Double Barrels [J]Road Machinery \& 625 Construction Mechanization,2015,32(09):94-96.

626 [17] Gao Xin. The Dust Removal System Research of Double Drum Type Continuous Regeneration Asphalt Mixing 627 Equipment[D]. Changsha University of Science and Technology,2015.

628 [18] Zhong Peihui. Research on Metering System in the Continuous Drum Asphalt Mixing Plant[D]. Chang'an University, 6292013

630 [19] Chi Fengxia, Zhang Xiaoning, Lu Yanqiu, Wang Lijian. Application of Double Barrel Drum Mix Plant in Producing 
631 Asphalt Mixture [J]. Road Machinery \& Construction Mechanization, 2007(11):33-35.

632 [20] Yin Xiaoqin, Zhao Shouming, Xie Jun, et al. Theoretical Research on Rational Rotation Speed of Twin-shaft Mixer [J].

633 Journal of Wuhan University of Technology, 2010,32(10): 108-111.

634 [21] Zhang Chenguang, Jiao Shengjie, Xie Liyang, et al. Modeling and simulation of material curtain density for asphalt

635 mixing plant rotary dryer $[\mathrm{J}]$. Journal of Huazhong University of Science and Technology (Natural Science 636 Edition),2017,45(5):55-60.

637 [22] Xie Liyang, Wang Xue, Zhang Chenguang. Analysis on Material Particle Motion in Drying Drum of Asphalt Mixing

638 Plant[J]. Road Machinery \& Construction Mechanization, 2011,28(10):57-60.

639 [23] Shi Huiqi. Simulation of Mixing Asphalt Mixture Based on EDEM[D]. Xian: Chang'an University,2017.

640 [24] Zhang Shengjun. Study and Simulation Analysis of the Twin Horizontal Shaft Mixer for Asphalt Mixture Mixing 641 Experiment[D]. Xian: Chang'an University, 2018

642

643

644 